\title{
Ripple Effect Mapping of Youth \& Adult Dyad Pairs Demonstrating Community Impact from iCook 4-H Intervention
}

Sina J.E. King

Follow this and additional works at: https://researchrepository.wvu.edu/etd

\section{Recommended Citation}

King, Sina J.E., "Ripple Effect Mapping of Youth \& Adult Dyad Pairs Demonstrating Community Impact from iCook 4-H Intervention" (2017). Graduate Theses, Dissertations, and Problem Reports. 5982. https://researchrepository.wvu.edu/etd/5982

This Thesis is protected by copyright and/or related rights. It has been brought to you by the The Research Repository @ WVU with permission from the rights-holder(s). You are free to use this Thesis in any way that is permitted by the copyright and related rights legislation that applies to your use. For other uses you must obtain permission from the rights-holder(s) directly, unless additional rights are indicated by a Creative Commons license in the record and/ or on the work itself. This Thesis has been accepted for inclusion in WVU Graduate Theses, Dissertations, and Problem Reports collection by an authorized administrator of The Research Repository @ WVU. For more information, please contact researchrepository@mail.wvu.edu. 


\title{
Ripple Effect Mapping of Youth \& Adult Dyad Pairs Demonstrating Community Impact from iCook 4-H Intervention
}

\author{
Sina J.E. King, B.S., M.Ed. \\ Thesis submitted \\ to the Davis College of Agriculture, Natural Resources \& Design \\ at West Virginia University \\ in partial fulfillment of the requirements for the degree of \\ Master of Science in \\ Animal Nutritional Sciences
}

Melissa, D. Olfert, DrPH, MS, RDN, LD, Chair

Joe Moritz, PhD.

Amy Root, PhD.

Department of Animal \& Nutritional Sciences

Morgantown, West Virginia

July 2017

Keywords: Ripple Effect Mapping; Youth; Dyad: Impact Mapping; Implementation and Dissemination; Community; Sustainability

Copyright 2017 Sina King 


\section{ABSTRACT \\ Ripple Effect Mapping of Youth \& Adult Dyad Pairs Demonstrating Community Impact \\ from iCook 4-H Intervention}

\section{Sina King}

Introduction: Creating effective dissemination and implementation tools within community based, obesity prevention research is needed to bridge the current science to practice gap. Ripple Effect Mapping (REM) using Community Capitals Framework (CCF) is a community impact evaluation tool that is hypothesized to positively capture activity during dissemination within community programs. Although REM is a proposed impact evaluation method, it has not been widely adopted within the research sector. In order to facilitate the translation of research into evidenced based practice, a stepwise process must be described and tested to determine efficacy and effectiveness, followed by a method to translate findings into useable and understandable information for the immediate users, the community, and larger public.

Purpose: The purpose of this study was to examine REM as an effective impact evaluation tool in determining participants' (youth/adult dyads) perceptions of the ripple effect of a 24 month, iCook 4-H multistate intervention program on self, family and community for future dissemination.

Methods: Seventy dyad ( $\mathrm{A}=$ adult, $\mathrm{Y}=$ youth) participants $(35=\mathrm{A}, 35=\mathrm{Y}$ ages 9-10 years) participated across 5 states (10 groups; ME, NE, SD, TN, WV). Three core themes of iCook 4-H were assessed: cooking, eating and playing together. Group dyads responded to open ended questions by leader driven dialogue about ways in which the iCook program has affected the individual, family and community. Three main questions were asked: 1) what are people doing differently as a result of the iCook program; 2) who has benefited from the iCook program and how; 3 ) are there changes in the way community groups and institutions do things as a result of the iCook program? Questions and dialogue were recorded by trained note-takers using a template with set instructions. Directed data content analysis was used to determine individual, family and community impact.

Results: Participants reported adopting new behaviors such as an increase in physical activity, frequency of trying new foods were increased and improved communication skills as well as increased harmony within family units. Directed content analysis resulted in one theme, seven categories with eight subcategories, and 41 supporting subcategories. Participants reported positive family behavior change affecting all capitals within the CCF leading to an amplified awareness of the importance of togetherness.

Conclusions: Findings indicate that the REM evaluation tool was an effective approach in determining participant perceptions for future dissemination and implementation. Additionally, findings show youth obesity prevention programs such as the iCook 4-H program have the potential to positively affect self, families and communities. Applying a tool such as REM can be used by researchers, community members and participants as an effective evaluation tool to demonstrate through a visual mapping image, the positive effects of obesity prevention programs to further the dissemination and implementation mileage, replicability and sustainably. 


\section{ACKNOWLEDGEMENTS}

I would first like to thank Dr. Melissa Olfert for her guidance and support throughout my graduate degree, as well as the opportunity to work as a student within her research lab. Her time, expertise and mentoring over the past two years have helped tremendously in the completion of this work.

I would also like to thank my additional committee members, Dr. Amy Root and Dr. Joe Moritz for their support and kind words throughout my graduate degree experience.

Next, I would like to thank my team members within the Lifestyle Intervention Research Lab, who I feel became family over the last two years with their unwavering support and continuous encouragement. I have learned so much from you all, and without you, this work would not have been possible.

I would also like to thank my family members, fellow interns, and the rest of the iCook team for their support over the course of my two years at West Virginia University. My journey here has been a positive one with the relationships I have had the privilege to build with you all. 


\section{TABLE OF CONTENTS}

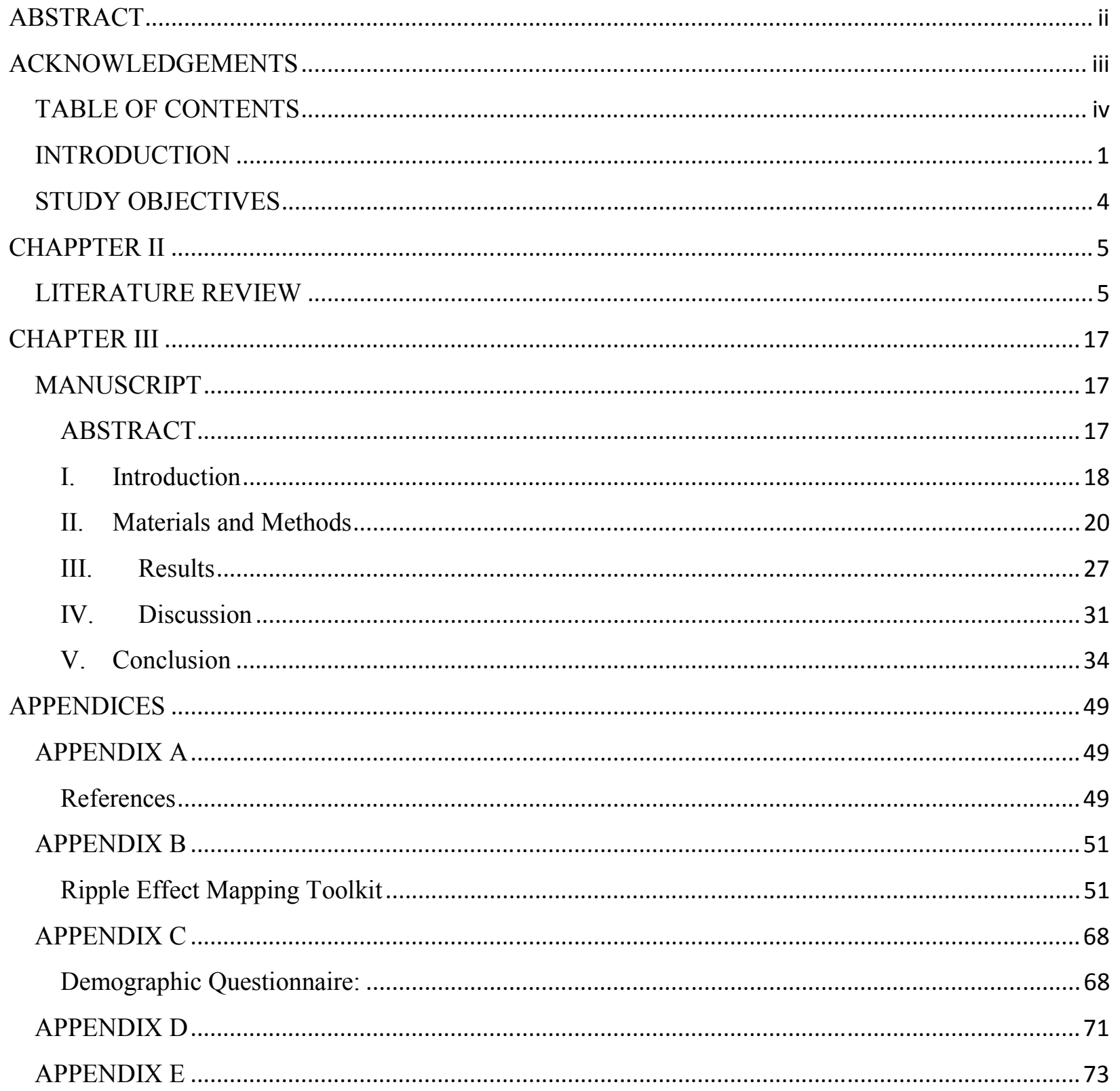




\section{CHAPTER I INTRODUCTION}

iCook 4-H is an obesity prevention program that was developed from the communitybased participatory research (CBPR) approach and supported by the Agriculture and Food Research Initiative Grant from the USDA National Institute of Food and Agriculture, Childhood Obesity Prevention: Integrated Research, Education and Extension to Prevent Childhood Obesity. This multistate partnership is comprised of five state experiment stations including Maine, Nebraska, Tennessee, South Dakota and West Virginia. The iCook 4-H program is a 5year project for 9-10 year olds and their primary adult meal preparer. The research team adapted two preexisting 4-H curricula, Youth in Motion and Fast Foods, combined with additional resources including family mealtime, MyPlate and food safety to better address childhood obesity.

The iCook 4-H program emphasized, "learning by doing" through skill building and increased knowledge in healthy lifestyle decisions with dyad based learning. The program's 6lesson curriculum focuses on multiple factors in addressing the obesity epidemic and is grounded in the Social Cognitive Theory (SCT), as well as the Experiential 4-H Learning Model. The SCT theory encompasses the approach that individuals learn by watching others, and at a young age, children learn to emulate feeding and behavior practices done by parents. Using a dyad approach with children and parents working together and learning from each other embodies this theoretic concept.

During the iCook program the parent/child dyad learn the importance of healthy lifestyle choices by participating in activities that promote healthy behaviors, team building, goal setting, 
family-meal discussions, eating together, physical activity, and acquiring new cooking skills. This program's objective is to determine whether an intervention such as iCook 4- $\mathrm{H}$, through building foundational skills for culinary practices, increasing family meals and physical activity, can positively impact the health of dyads (youth and adults) within a community setting.

Year one of the iCook 4-H program was comprised of the pilot intervention where participants attended 6 biweekly sessions focused on cooking, eating and playing together with goal setting and website activity completed intermittently. Assessments were captured at baseline and four months; process evaluations and fidelity took place following each session during the pilot intervention.

Year two and three of the program involved recruitment, randomization of control/intervention participants, and six biweekly sessions. After program completion, intervention participants continued to stay connected through website video, picture competitions, monthly newsletters and seasonal boosters for two years following the 14-week intervention. Assessments and program evaluations were completed at baseline, four, twelve and 24 months. Process evaluations and fidelity were also complete following each session.

Following the intervention, dissemination took place in year four and five with the help of Cooperative Extension in each state. Eight biweekly sessions were conducted and participants engaged in website activity throughout program completion. Program evaluations were captured at baseline and 4 months. Process evaluations and fidelity were obtained following each session. A teen assistant leader component was added in dissemination to promote teens as teachers.

As part of the dissemination process, a tool entitled eB4CAST was used to create infographics capturing participant feedback and perceptions, as well as utilizing publically 
available data to create an environmental profile of dissemination sites. Dyad participants were led through a ripple mapping experience where they shared their perceptions of community impact. This information was transformed into an infographic that was tailored specifically for the geographical location of participants within the iCook 4-H program and given to participants, session leaders, and state extension experts as a visual of how iCook impacted the community. The infographics created are part of a larger framework titled, eB4CAST, that works to capture implementation and dissemination of evidence based research programming.

The purpose of this current study was to examine the ripple mapping experience known as Ripple Effect Mapping and to determine if this evaluation tool was effective in translating participants' (youth/adult dyads) perceptions of the iCook 4-H multistate intervention program on self, family and community. To our knowledge, a stepwise process of the impact evaluation tool, Ripple Effect Mapping, analyzed using direct content analysis has not been documented. 


\section{STUDY OBJECTIVES}

The study's primary objective was to determine Ripple Effect Mapping's usefulness in defining positive outcomes as an impact evaluation tool. Additionally, this study looked at participants' (youth/adult dyads) perceptions of the ripple effect of a 24 month, iCook 4-H multistate intervention program on self, family and community. It is hypothesized that the youth obesity prevention program, iCook 4-H, will positively affect self, families and communities. Further, Ripple Effect Mapping used as an impact evaluation tool, will effectively determine positive outcomes of the iCook 4-H program. 


\section{CHAPPTER II \\ LITERATURE REVIEW}

\section{Introduction}

Change within a community can take place gradually or relatively quickly due to a new organization, community resource, research innovation or a variety of other new developments. Within research, innovative programs developing new understandings in health interventions can also create change and produce significant positive results for a target population. However, the bridge between community change and change seen within a measured research setting varies greatly. In the healthcare field, findings within evidence-based research have been estimated to take roughly 17 years to be adopted into community practice. Additionally, only 50 percent of these innovative programs are sustainable within a community overtime (Bauer, 2015). This gap in science to practice has not gone unnoticed however. Funding entities for health interventions have taken action; now requiring implementation and dissemination plans for evidenced-based research to help bridge the science to practice gap that currently exists (Bauer, 2015; Meyers, 2012).

With increased funding opportunities for programs adopting implementation and dissemination frameworks, this area of study has become increasingly popular. Several frameworks have been established as a result of implementation science that focus on evidencebased programs in community-based research, outlining methods that can be used to improve public health outcomes (Meyers, 2012). An impact evaluation is a process and tool that enables researchers, participants and community members to understand the impact a health promotion program had on its targeted population and to use that information to better improve future 
programing (Lobo, 2014). Although frameworks outlining the needed steps for implementation and dissemination of health promotion programs have increased, the tools and methods that make up these frameworks are lacking. In order to understand and assess program outcomes for future positive change, an impact evaluation process known as Ripple Effect Mapping (REM) was created (Emery, 2015; Hansen, 2012). REM is a technique used to document various impacts, positive outcomes and changes that result from a particular program through the use of the Community Capitals Framework (CCF) (Nathaniel, 2013; Emery, 2006).

The REM evaluation approach also serves as a feasible and practical community assessment tool for stakeholders and the surrounding community, taking into consideration the lack of time, manpower and funds typically applied for community program evaluations (Emery, 2015). This evaluation technique has been found to be more effective when compared to previously used experimental research that yielded lesser useful information and failed to report the detailed context of the program being assessed (Hansen, 2012). However, little evidence can be found detailing a stepwise process of REM impact evaluations and the specific outcomes this evaluation tool has had on youth centered community programs.

Evidenced-based research within the healthcare field is a well-known area of study, targeting the undesirable trend of overweight and obese individuals within all age groups. Obesity in adults is linked to increased risk of high blood pressure, type 2 diabetes mellitus, dyslipidemia, stroke, coronary heart disease, mental illness, and multiple types of cancer (CDC, 2012). Similarly, children who are overweight or obese throughout childhood have an increased risk of continuing this trend into adulthood along with countless other health problems (CDC, 2015). Extensive research has been conducted on reasons for childhood obesity such as linking obese parents to an increased likelihood of obese children among other factors (Brandt, 2004). 
Due to the ever increasing obesity epidemic, funds are not only being funneled to implementation and dissemination science, but to research projects addressing community, youth obesity prevention programs as well.

To promote obesity prevention in youth, a multistate research project titled iCook $4-\mathrm{H}$ that focuses on childhood obesity prevention by applying behavioral, theoretical concepts to intervention strategies that promote healthful behavior patterns was formed. The program emphasized "learning by doing" through skill building and increasing knowledge in culinary competence, meal time and physical activity. The curriculum is grounded in Social Cognitive Theory (SCT) and encompasses the approach that individuals learn by watching others, as well as highlighting external and internal social reinforcement (Bandura, 2012). Interventions such as the iCook 4-H program adopt innovative approaches that are tailored to the needs of the individual and specific community by utilizing multiple community resources. To determine if a project such as iCook 4-H was successful in creating positive outcomes, both in the community and for individual youth, implementing an impact evaluation method such as REM is key.

The aim of this review is to determine whether the current literature on the impact evaluation tool titled REM, is sufficient in order to report and verifty outcomes of youth obesity prevention programs such as iCook 4-H. Without impact evaluation tools, programs within a community are unable to justify the program need, provide evidence of positive outcomes, create program sustainability or make decisions on necessary versus unnecessary program methods for the future (Baker, 2011; Child trends, 2007). If the obesity prevalence among youth is expected to change, justifying obesity prevention programs within community-based research through impact evaluations is needed. Impact evaluations can be used for a variety of research platforms, 
however, this review will focus on impact evaluations related to youth obesity prevention and health promotion programs within communities.

\section{How and Why Capturing Program Impacts is Essential}

Impact evaluations and studies requiring reported outcomes of evidenced-based community programs have become increasingly popular in the United States in order to translate research within controlled settings into community-based practice (Rennekamp, 2009). There are several different types of evaluation methods including formative, process/implementation, outcome/effectiveness and impact evaluation. In the same way, impact evaluations can be broken down into further subgroups, all of which identify and provide evidence on met objectives and estimations on perceived success rate (Goldstein, 2015). Impact evaluation tools and program design research have increased due to the ability to receive additional program funding through validating positive program outcomes (Rennekamp, 2009). In addition, community programs can receive evidence on positive outcomes to improve sustainability of evidence-based research over time. Understanding the effects of positive behavior change through obesity prevention programs, will better assist future research in determining ways to decrease the prevalence of obesity in youth who are in need of building skills and confidence.

In order to determine if current programs and funding are creating positive outcomes and change, both qualitative and quantitative research in the form of evaluations prove beneficial. Recently, an area in which program logic models and impact evaluation methods have been used more widely in community programs includes obesity prevention and intervention; more specifically youth obesity prevention and intervention programs. This trend can be credited to the rise in overweight and obese individuals within the United States (CDC, 2012). According to the Centers for Disease Control and Prevention, childhood obesity has more than doubled in children 
and increased in adolescents nearly fourfold in the past 30 years. Due to these findings, communities around the nation have developed school, community, and home-based interventions for at risk youth to over-time, reverse this trend (Wang, 2013). Community leaders and research teams across the nation have recognized the need for involvement and have created programs that promote healthful lifestyles.

Quantitative research with obesity interventions, such as the comparative meta-analysis research, showed that school-based obesity interventions with community components are currently one of the most effective (Wang, 2013). Correspondingly, research groups such as the Harvard Prevention Research Center (HPRC) and the Healthy Campus Research Consortium (HCRC) have paired with various community agencies to implement youth programs that aim to improve overall health and knowledge (HPRC, 2015, Linnell, 2014). Unfortunately, the documented impact evaluations and post program assessments surrounding these programs and research are lacking; a chief reason being impact evaluations are a relatively new focus area on community program evaluation results (Rennekamp, 2009). Sources used to obtain information for an impact evaluation include program records, program staff and participants, collaborating agencies, community leaders, outside experts, national databases, and participant focus groups (Kellogg, 2004). REM uses participants, community members and program stakeholders to determine positive program outcomes.

Although program evaluations justify community funds spent, impact evaluations also maximize community involvement, conveys complex concepts in an understandable way and identify unplanned consequences or successes throughout the program (Darger, 2014). The evaluation process gives program stakeholders the evidence and material needed to continuously improve and make positive changes within its program (Emery, 2006). Increased information 
through impact evaluations lead to increased efficiency and effectiveness within community programs. These evaluation methods lead to innovative ways in which programs operate and increase community motivation, which is a vital part in any community change (Darger, 2014; Rennekamp, 2009). However, further research and the utilization of impact evaluations are needed to better assess REM's effectiveness in reporting specific objectives met in evidencebased programs.

\section{Different Approaches of Impact Evaluations}

As stated previously, impact evaluations used in the community setting have become more prevalent within youth programming. Emery, Higgins, Chazdon, and Hansen give three approaches to REM impact evaluations for communities including web mapping, in-depth rippling, and theming and rippling. Key differences and similarities are found for all approaches, however each approach has the capacity to find both direct and indirect impacts for a completed community program (Emery, 2015). Web mapping is used during focus group sessions to determine the program's short, medium and long-term impacts on the community through a visual mapping process. In-depth rippling is termed as an advanced discussion of the most impactful outcomes of the program and events that took place. Theming and rippling is the final approach that uses participant focus groups to report the program's impacts and major themes, as well as examines the interconnectedness of these themes generated (Emery, 2015).

Generally, each REM process follows similar steps in order to conduct a post program impact evaluation session. The concept behind a REM session deals with the brains associative thought processes that are linked to integrated concepts by beginning at a central point and linking events together. The process of linking together themes, ideas and outcomes is considered the core of the theming and rippling evaluation process. At the beginning of a REM 
session, the facilitator will begin the discussion with the program title placed in a central area on a drawing medium (Hansen, 2012). From this central point, the questions asked by the facilitator will prompt focus group participants to make connections between the positive outcomes and community capitals knows as CCF (Baker, 2013; Emery, 2006). This brainstorming activity is recorded by a group facilitator that documents the participants' thoughts on how one event or outcome affects another; this is termed as mapping the "ripples" that have taken place (Baker, 2013).

During an evaluation session each participant is given the opportunity to discuss his or her thoughts on how connections are made between the community capitals and the program topic (Hansen, 2012). Following the REM session, the facilitator and/or research team must analyze the information recorded; in this way, the participants, community and program stakeholders will obtain useful data in a visual mapping image on participant perceptions and how to improve the program in the future (Hansen, 2012; Baker, 2011). There are various approaches that can be used for different platforms of programs. For a youth, obesity prevention focused program, the theming and rippling form of REM is most effective in simplifying the conceptual idea of linkages among all of the community capitals.

\section{Using Community Capitals Framework for Community Change}

The Community Capitals Framework (CCF) is an approach that was created to better analyze how successful communities work, and acts as a platform to determine the successfulness of other communities, and their programs (Emery, 2006). Research has shown that sustainable and entrepreneurial communities possess seven areas of strength and resourcefulness that are interrelated and combined to promote economic development and viable community enhancements (Emery, 2006; Fey, 2006). These seven areas are known as 'capitals,' or resources 
that the community uses to build upon and form new assets (Priest, 2013). These seven capitals include social, human, cultural, natural, built, financial and political capital (Baker, 2011). Although each capital and resource is vital for a successful community to grow and possess sustainable economic development, social capital represents the fundamental backbone of a successful community. Without the connections among individuals and groups within the community, the bonding and bridging of human relationships and therefore optimal community function will not take place (Fey, 2006).

By combing social capital with the remaining resources or assets, some including monetary funds, natural properties, infrastructures and government positions, health promoting community programs will increase the number of met objectives. The breakdown of each capital and asset is as follows: Built capital refers to the community's infrastructures, roads, transportation systems, power, supplies structures, water and sewer systems. Financial capital refers to the monetary funds available to the community. Political capital refers to community stakeholders in positions to make change, rules and regulations such as local government officials, local business leaders, and youth leadership roles. Natural capital refers to the natural resources within the community such as parks, rivers and local terrane. Cultural capital is the knowledge and values individuals obtain from their heritage and ethnic background. Finally, human capital refers to the skills and abilities of individuals that can be used in one's occupation (Baker, 2011). This comprehensive inventory of all assets can be used to help program participants understand what benefits he or she has gained along with the community through completing a specific program. By combining each capital and resource within the community, as well as bridging the bonds and human relationships formed, positive change is probable. 
The CCF platform and its seven capitals used within REM evaluations utilize an Appreciative Inquiry approach for community and program assessment (Priest, 2013). The Appreciative Inquiry was developed to help corporations become more effective by adopting an overall way of thinking that focusing on solutions and positives; the belief being that focusing on positives will in turn create more solutions and positives. Likewise, if a group or organization focuses on the program or corporation's problems, the organization will ultimately create more problems (Baker, 2013; Priest, 2013). The theoretical basis behind focusing on positive aspects was developed from the Social Constructionism theory and ultimately encompasses the 'glass is half-full' attitude (Priest, 2013). In general, what individuals talk about, decides and controls what that individual cares about and acts upon. Because of this theoretical concept and approach, CCF and REM focus on the positive aspects within the community and program to determine the positive change created. The CCF based from Appreciative Inquiry can be used in impact evaluations to better determine positive change for a variety of program platforms, specifically youth focused to keep participants and community members motivated with sustainable involvement.

\section{Youth Engagement Focus in Health Promotion for Positive Change}

In order to determine effective ways in which community programs can influence the youth obesity epidemic currently and in the future, program impact evaluations are needed. Youth development researchers have found that programs utilizing connections created between nonfamily member adults with youth during community programs, have supportive and meaningful interactions that influence youth in a positive way. These meaningful connections and interacts between non-family adult, youth pairs are considered social capital bondages that can affect other capital resources within the community (Nathaniel, 2013). These findings have made it 
possible to identify a strategy for youth to determine the impact of youth programing on community developments. An inquiry-based approach is used to reach and educate youth, as well as determine outcome measures (Baker, 2011). Using the REM evaluation process will ultimately yield positive results. Baker, Calvert, Emery, Enfield, and Williams found that mapping community capitals with youth groups is key in determining program impacts because the inquiry-based approach along with the CCF make abstract ideas about community assets into understandable ideas for youth participants (Baker, 2011; Emery, 2006). Youth programing is a critical element in the process of community change and evaluating impacts and program outcomes (Nathaniel, 2013).

As previously stated, research and funding entities have furthered the development of health promotion and obesity prevention programs in hopes of reversing the obesity epidemic in youth. Research organizations such as the Harvard Prevention Research Center (HPRC) and the Healthy Campus Research Consortium (HCRC) have joined with various community agencies to implement youth programs that aim to improve overall health and knowledge. The HCRC has paired with universities across the nation to form the iCook 4-H multistate project focusing on childhood obesity prevention. This project is an innovative method that uses adult, youth dyads to work with one another through eating together, cooking together and playing together. Similarly, projects such as The Childhood Obesity Research Demonstration (CORD) and The Boston Racial and Ethnic Approaches to Community Health: Obesity and Hypertension Demonstration Project (REACH) are current projects within the United States that's objectives are to promote healthy lifestyles through diet, physical activity and education (PHPR, 2015; Olfert, 2015). Unfortunately, sustainable community based programs focusing on a variety of educational areas for youth at a large scale are extremely limited. Community-based 
interventions preventing and/or reducing childhood obesity have typically been small, efficacy trials; making the implementation of evidenced-based research programs into community practice for youth extremely difficult (Welsby, 2014). Impact evaluations such as REM would provide these research organizations with evidence of program outcomes and participant perceptions as to what works best in preventing and reversing the obesity epidemic in order to begin the shift of science to practice within communities.

\section{Conclusions and Future Research}

Using REM as part of a preexisting obesity prevention program's dissemination and implementation process can help determine various outcomes of obesity prevention programs like iCook 4-H. Current research using impact evaluations to determine positive outcomes in communities has shown an increased motivation within the community, increased funding, as well as strengthened community member involvement due to individual and community awareness and mindfulness (Darger, 2014; Emery, 2015). Thus, by using a REM evaluation tool for obesity prevention programs, researchers can increase their understanding of implementing sustainable, healthy lifestyles and dietary programs within an at risk youth population.

To understand program effects and outcomes, evaluation tools such as REM can be used to benefit participants, community members and researchers by providing visual imaging through the ripple mapping of program impacts in an understandable way. Unfortunately, sparse research on REM specifically used for youth health-promotion community programs have been published to date. Various information on how to conduct a REM focus group session for health-related programs exits; however, published, stepwise examples of these focus group sessions are lacking. Current information on REM shows that when used, REM not only conveys complex concepts in an understandable way for youth, but maximizes involvement, as well as identifies 
unplanned consequences or successes throughout the program (Darger, 2014). Additional research is needed to definitively verify the use of REM as an appropriate evaluation tool within community based, obesity prevention research to better support dissemination and implementation science. 


\section{CHAPTER III \\ MANUSCRIPT}

\section{ABSTRACT}

\section{Using Impact Mapping in a Culinary Program Targeting Youth and Adult Dyads}

Sina J.E. King, $M S^{l}$, Allison M. Morris, $B S^{l}$, Rebecca L. Hagedorn, $B S^{l}$, Makenzie L. Barr, BS ${ }^{l}$, Oluremi A. Famodu, MS, RDN, ${ }^{l}$ Sara M. Colby, PhD, RDN ${ }^{2}$, Kendra K. Kattelmann, PhD, RDN ${ }^{3}$, Lisa Franzen-Castle, PhD, $R D N^{4}$, Adrienne A. White, PhD, $R D N^{5}$, Barb Baker ${ }^{5}$, Melissa D. Olfert, DrPH, RDN ${ }^{l}$

West Virginia University ${ }^{1}$, The University of Tennessee Knoxville ${ }^{2}$, South Dakota State University ${ }^{3}$, University of Nebraska Lincoln ${ }^{4}$, The University of Maine ${ }^{5}$

Introduction: Effective dissemination and implementation (D\&I) tools evaluating research to practice for community based obesity prevention interventions are needed to bridge the current research to application gap. Ripple Effect Mapping (REM) using the Community Capitals Framework (CCF) is a community impact evaluation tool that is hypothesized to positively capture how the research intervention affected multiple levels within communities.

Objective: To implement and assess the use of REM in a childhood obesity prevention program (iCook 4-H) to show impact within communities.

Methods: Seventy dyad ( $\mathrm{A}=$ adult, $\mathrm{Y}=$ youth ages $9-10$ years) participants $(35=\mathrm{A}, 35=\mathrm{Y})$ participated across five states (ME, NE, SD, TN, WV) in ten REM sessions, 24 months' post iCook 4-H intervention. The three core themes of the iCook 4-H program were assessed: cooking, eating and playing together. Dyads responded to open ended questions by leaderfacilitated group-dialogue regarding how the program affected the individual, family and community. Three main questions were asked: 1) what are people doing differently as a result of the program; 2) who has benefited from the program and; 3) how are there changes in the way community groups and institutions do things as a result of the program? Questions and dialogue were recorded by trained note-takers using a template with set instructions, which was followed up with directed data content analysis to determine individual, family and community impact.

Results: Participants reported adopting new behaviors such as an increase in physical activity, frequency of trying new foods, and improved communication skills as well as increased harmony within family units. Directed content analysis resulted in one theme, seven categories with eight subcategories, and 41 supporting subcategories. Participants reported positive family behavior change affecting all capitals (Human, Social, Cultural, Political, Natural, Built, and Financial) within the $\mathrm{CCF}$, leading to an amplified awareness of the importance of togetherness.

Conclusions: Community impact evaluation incorporating the REM approach effectively identified participant perceptions of the iCook 4-H program and provided direction for future implementation and dissemination tools. Additionally, findings show youth and adults in childhood obesity prevention programs such as the iCook 4-H program have the potential to positively affect one's self, family and community.

Key Terms: Ripple Effect Mapping; Youth; Dyad: Impact Mapping; Implementation and Dissemination; Community; Sustainability 


\section{Introduction}

Research examining effective implementation and dissemination of community programing has increased within the last 25 years (Meyers, 2012; Rennekamp, 2009). Subsequently, there has been an increased need for methods that systematically evaluate the impact of the implemented and disseminated programming; these methods can help in bridging the research to practice gap (Meyers, 2012). To understand the reach and impact of evidenced based programs within communities, documentation of stepwise tools that evaluate this are needed (Bauer, 2015). One approach that intervention programs can use to accomplish this is an impact evaluation method that can be used as part of a larger implementation and dissemination framework (USDA, 2015). Evaluations of program impacts range from measured increased motivation within the community, strengthened community member involvement, positive lifestyle alterations and increased program funding resulting in short-term sustainability (Darger, 2014; Rennekamp, 2009). Yet, there is a lack of published community impact evaluation tools using a comprehensive, stepwise process to aide in replication and dissemination with mainstream evaluation measures to support programing (Lobo, 2014; Meyers 2012).

Impact evaluation is a process and tool that enables researchers, participants and community members to understand the efficacy and reach of health-based promotion programing on its targeted population; furthermore, this evaluation information can improve future programing (Lobo, 2014). Program guidelines should take into consideration the program's resources, target population and time stipulations, as well as the practicality and feasibility for program location. Additionally, the evaluation used should produce credible and accurate results along with creating useful information on ways in which program effectiveness can be improved (CDC, 2011). Ripple Effect Mapping (REM) is one such type of impact evaluation that assesses how 
effectively programs reached their goals (Emery, 2015). The adoption of an evaluation tool such as REM can assist community programs in producing evidence of positive outcomes while simultaneously moving forward into program dissemination.

REM is a type of impact evaluation used to document various impacts, positive outcomes and changes that result from a particular program through the use of the Community Capitals Framework (CCF) (Emery, 2006, Nathaniel, 2013). CCF is an approach that was created to better analyze how successful communities work, and acts as a platform to determine the successfulness of other communities, and their programs (Emery, 2006). Research has shown that sustainable and entrepreneurial communities possess seven areas of strength and resourcefulness that are interrelated and combined to promote economic development and viable community enhancements (Emery, 2006; Fey, 2006). These seven areas are known as 'capitals,' or resources that the community uses to build upon and form new assets (Emery, 2006). The REM evaluation approach uses the CCF to document programmatic impacts on participants, stakeholders and the surrounding community (Emery, 2009). This evaluation tool has been found to be more effective when compared to previously used evaluation tools analyzing experimental research that yielded less useful or detailed information (Hansen, 2012). Therefore, the use of REM can help community and program stakeholders determine positive program outcomes within the community health promotion sector (Baker and Johannes 2013).

Although REM is a proposed impact evaluation method, it has not been widely adopted within the research sector. To facilitate the translation of research into evidenced based practice, a stepwise process must be described and tested to determine efficacy and effectiveness, followed by a method to translate findings into useable and understandable information for the immediate users, the community and larger public (Meyers, 2012). The lack of investigation in 
impact evaluation tools for community interventions that promote sustainability can begin to be remedied by utilizing existing tools that contribute to the need of disseminated, evidenced-based programs within the community sector (Wandersman, 2008).

To our knowledge, there is no comprehensive, stepwise methodology of a REM evaluation tool that uses content analysis and word frequencies to determine and compare participant perceptions. This manuscript details the exploration of using REM in a detailed stepwise form to evaluate and understand youth and adult participant perceptions on how the iCook 4-H program impacted the individual, family and community. Directed content analysis was used to create homogeneity among REM evaluations for future use and as a sustainable measure for the implementation and dissemination of programs.

\section{Materials and Methods}

\section{iCook 4-H Obesity Prevention Program}

The data analysis of REM was part of a broader research process assessing quantitative outcomes of the obesity prevention program titled iCook 4-H. iCook 4-H was a two-year controltreatment intervention study conducted by a multistate team of researchers in five states (Maine (ME), Nebraska (NE), South Dakota (SD), Tennessee (TN), West Virginia (WV). The aim was to prevent childhood obesity using a youth-adult dyad model. The intervention was a 6-session curriculum taught over 12 weeks with a focus on cooking, eating and playing together (Miller et al, 2016; Sorenson et al, 2015; Donaldson et al, 2014; Franzen-Castle et al, 2014). The curriculum was based on the Social Cognitive Theory (Bandura, 2012) and the 4-H approach of “learning by doing” (National 4-H History Preservation Team, 2017). Following the intense intervention, over the next two-years activities for the treatment dyads included seasonal booster 
sessions, monthly newsletters and making and posting videos/pictures on the study website. Assessments included anthropometrics, self-reported adult height and weight, tanner stage, blood pressure, participant process surveys, and fidelity surveys completed at baseline, four, 12 and 24 months.

While traditional evaluation measures of surveys were used to assess program effectiveness, the research team identified REM as an alternative method to surveys for evaluation of the iCook 4-H program (Mathews et al, 2015). The objective was to use the REM structure with youth-adult dyads to allow them to reflect on program impacts.

\section{Methodology}

Goals and objective. The goal was to investigate the impact iCook 4-H program had on youthadult treatment dyads following the two-year intervention. The objective was to generate a visual picture of the qualitative feedback gathered through small group discussions of treatment dyads, analyze the data collected from data report templates and use word frequencies to ensure consistency across data gathered.

Study Design. An evaluation of the program impacts on youth-adult dyads following the 2-year program using the qualitative Ripple Effect Mapping technique took place. The technique is a 90-minute structured group activity with sequential questioning designed to elicit reflection and feedback from participants. A map, a visual picture of responses, is created by a trained facilitator, as the discussion ensues. Trained note taker(s) record session discussions and input data into a report template. Across the five states, 10 discussion groups were held and four of those were video recorded to further enhance data analysis. The Institutional Review Committees for the Protection of Human Subjects at the five universities approved the study. 
Participants. Treatment dyads $(n=35)$ who agreed to participate in an additional study following the 24 month iCook 4-H study were the study participants. Participants received \$50/dyad for participation.

Recruitment. Treatment dyads were recruited at the 24-month research assessment period ( $\mathrm{n}=$ 182), to share opinions and experiences about the iCook 4-H program. Names of interested participants were recorded and contacted at a later date to schedule times for group discussions of 6-10 persons.

Training of facilitators. Facilitators were identified within each state and trained using online videos (Baker and Gill, 2015; Baker and Johannes, 2013). In addition to the training videos, written training toolkits were created by researchers that gave further detailed instructions and a checklist for steps to follow. In Table 1 is the checklist used to detail instructions. Training and guides helped to ensure homogeneity across facilitators for optimal data comparison. Training and protocols for note takers.

The training document also described what each facilitator should do during the REM session. Each note-taker was also trained on using a report template so that both youth and adult comments could be captured along with the usage of the CCF. These documents have been included in the final session of the iCook curriculum instructor's guide for future leaders to use REM as a culminating reflective activity for the program.

Note-takers were identified for each discussion group. They were trained by facilitators to use report templates to record statements and to denote whether statements came from youth or adults by placing a Y or A by the comment. Group dynamics, such as participant placement around the sitting area, were recorded. At the end of the discussion, the note taker recorded the 
REM impact of the most important or significant idea, most bridging among new people and most bonding among new people.

\section{$\underline{\text { REM Session Breakdown }}$}

Study Protocols.

Prior to the start of each discussion session, participants signed consent and media forms. Demographic questionnaires were collected. A standardized protocol including a structured leader guide were followed across all sites to assist in data management.

Participants were seated in a semi-circle in front of the mapping materials, attached to the wall. Guidelines for group discussions were reviewed and participants were asked to reflect on the 2-year study and the program impacts on cooking, eating and playing together.

The facilitator led an icebreaker activity that allowed youth and adults to focus on the iCook experience and aid in increasing participant comfort. The activity consisted of a question and answer matching game; these questions and answers were based on information included in the program (Table 1). Following the icebreaker activity, the facilitator led a brainstorming activity, recording on the side of the map, participants' responses about the most beneficial program aspects. Participants were asked to pair up (adult paired with adult; youth paired with youth) and interviewed one another about favorite memories during sessions. These topics were recorded by the facilitator on the side of each map and referenced by participants throughout the sessions to assist in dialogue when creating the map.

Following the brainstorming activity, the REM session began with an explanation as to why the session was being conducted and what participants could expect within the next 90-120 minutes. (Sample explanation found in Table 2). The explanation was followed by instructions 
on what community capitals were and how they would be used throughout the session.

(Descriptions of each capital found in Table 3). Participants were given a handout of the capitals for reference during the session. The community capitals were a way in which participants could relate positive impacts of the iCook 4-H program to effected resources within the community.

Succeeding this process, the program title was placed in a central area on a board (could have been a chalkboard, whiteboard, large poster board, or large pieces of paper placed together; sample mapping template in Figure 2). Group dyads ( $\mathrm{Y}=$ youth, $\mathrm{A}=$ adult) responded to leaderfacilitated dialogue about ways in which the program had impacted the individual, their family unit and/or their community through open-ended questions (Table 4). The facilitator then discussed with the group as to where the participants responses should be placed on the board in respect to the capitals. Each participant was given the opportunity to discuss and verbalize his or her thoughts on how connections were made between the questions asked and the community capitals. Adults were asked to allow all youth participants the opportunity to express his or her ideas first, with adults expressing ideas following youth comments. The facilitator documented the participants' thoughts on how one event or outcome affected another; this was termed as mapping the "ripples" that had taken place (Bauer, 2015; Baker \& Johannes, 2013).

Documentation of specific capitals relating to participant comments were discussed and recorded as well (completed sample map is in Figure 3.)

Note takers recorded participant statements, documented whether a youth or an adult made each statement using a $\mathrm{Y}$ or $\mathrm{A}$, and group dynamics (such as participant placement around the sitting area). Following the questions and community capitals discussion, the REM impact of the most important or significant idea, most bridging amongst new people and most bonding amongst new people were determined by participants collectively and recorded by the session 
facilitator and note taker (Table 5). This activity reflects the importance of social capital within a community, giving participants additional time to reflect on program events that lead to positive community cohesion.

Picture images were captured of the REM map without participants and then again with participants following the session; incentives were then distributed. Facilitators and note takers recorded the information created by the participants from the visual map into a data report template. Each mapping image, data report template and when applicable, video recorded session was sent out, blinded for review, to the Lifestyle Intervention Research Lab for data analysis. Facilitators were interviewed by the note-takers immediately following the REM session to document any additional limitations perceived to have occurred during the sessions and what the facilitator perceived as having worked best during the process.

\section{$\underline{\text { Analysis }}$}

The primary coding process of directed content analysis began using the data report templates completed by note takers for each REM session. The primary researcher studied line by the line, the report templates after first making general field notes. After coding was completed, the primary researcher restudied each report template to certify no other codes were missed. It was noted during analysis whether an adult or youth made the comment. Following this, codes were merged and summarized creating categories and subcategories for each. Two additional researchers reviewed each report template and discussed the theme, categories, subcategories and supporting subcategories, creating two additional subcategories during this process. To ensure accuracy of data report templates, two videoed REM sessions were viewed and compared to the data report templates. Accuracy was determined with the report templates and finalization of analysis took place after the second researcher consultation concluded. 
The rigor of data analysis within this study was gained though credibility, applicability, consistency and neutrality (Magilvy, 2011; Zhang, 2009). Credibility was achieved through long term investigation of subject matter, maps, data templates and testimonials given by each sites' facilitators. Member checking, otherwise termed as expert reviewer debriefing, took place through facilitator discussions to ensure there was an accurate depiction of participant perceptions during each REM session. Transferability was achieved through the completion of participant demographic questionnaires to establish representativeness of participants for applicability in future dissemination use. To achieve dependability of the data, a stepwise process prior to analysis was created for validity of the research findings, explained below.

Confirmability took place with the establishment of credibility, transferability and dependability along with research reflection during analysis to confirm minimal bias had occurred (Magilvy, 2011). These components confirm the study's rigor and allow the current findings to be applied to a larger scope of study within the implementation and dissemination of obesity prevention research.

The theories used during data analysis were both the SCT and Appreciative Inquiry framework based on Social Constructionism. Research supporting SCT shows that parents serve as role models for dietary habits, and at a young age, children learn to emulate feeding practices done by parents (Wang, 2009). When analyzing data, this theory was the basis of all interactions and categories created with the concept of togetherness. Based on these theories, it can be hypothesized that both adult and youth participants would work together to accomplish healthier food intake, and positive health behavior which would become more sustainable over time (Gurley-Calvez, 2010; Bandura, 2012). 
Appreciative Inquiry (Emery, 2006) is a method used to help enterprises become more effective by adopting an overall way of thinking that focuses on solutions and positives; the belief being that focusing on positives will in turn create more solutions and positives. The theoretical basis was developed from Social Constructionism and ultimately encompasses the 'glass is half-full' attitude. In general, what individuals talk about controls what the individual cares about and acts upon (Priest, 2013). By using this theoretical concept and approach, CCF within REM focuses on the positive aspects within the program to determine the positive changes created (Emery, 2006); thus acting as the second theoretical construct used throughout the analysis.

\section{Results}

\section{$\underline{\text { Demographics }}$}

Participant demographic characteristics are presented in table 6. Thirty-five dyads, youth (11.4 \pm 0.65 mean age; $51.4 \%$ male) and adults ( $41.9 \pm 6.3$ mean age) participated across the five states. Ten total REM sessions were conducted. Participants were primarily Caucasian $(\mathrm{n}=71.4 \%)$ and $59 \%$ of the adults had at least a bachelor's degree. The level of adult education ranged from elementary schooling $(\mathrm{n}=8.6 \%)$ to a Doctoral degree $(\mathrm{n}=5.7 \%)$, the completion of a Bachelor's degree $(\mathrm{n}=34.3 \%)$ was most prevalent. Youth gender was relatively equal with 51.4 percent of participants as male.

\section{$\underline{\text { Directed Content Analysis }}$}

Data analysis indicated the main, overarching theme of participant perceptions of iCook 4-H was: learning new skills together through trying new things (cooking, eating, \& playing together) 
leads to positive individual, family and community change. Within the all-encompassing, major theme, 7 categories with 8 subcategories, and 41 supporting subcategories were identified.

The first category was 'improved health.' This category was formed with 2 subcategories, these being:. 'playing with peers and family through exercise leads to better health;' and 'better disease management leading to improved overall health.' Six supporting subcategories, created the two subcategories. Within these subcategories participants expressed ways in which completing the program led to new changes within his or her life that reflected an improved lifestyle and subsequently improved health. One participant indicated that, "there are decreased medical expenses due to better health." Similarly, participants felt that they were engaging in more physical activity and stated that "increased physical activity and being more active causes more energy." This improved health category also includes participant perceptions of increasing fruit and vegetable consumption and feelings of becoming more fit, healthier, sleeping better and laughing more as a result of the program; all contribute to improved health, as well as better disease management (Figure 4).

The second category was 'increased community involvement.' This category was formed with 2 subcategories; these included 'increased community involvement with friends and peer groups' and 'increased community involvement through organizational groups.' Eight supporting subcategories reinforced and formed the 2 subcategories. Participants voiced perceptions of improved local business production and need due to buying fresh local produce and increased cultural awareness by trying different cuisines. Also, there was a perception of increased volunteering within the community and becoming "a role model because community members see me exercising more." (Figure 4). Additionally, participants expressed an increase in positively influencing peers, stating, "my friends and I spend more time together." 
The third category was 'increased participant knowledge' due to the iCook 4-H program. Two subcategories within this area were formed, the first: 'increased knowledge by trying new things' contained participant perceptions of trying new recipes, trying new flavors and spices, and increased friendships through learning new games together. The second subcategory, 'increased knowledge through education and new experiences,' was filled with new experiences by participants in learning how to read food labels, the knowledge of family member's likes and dislikes through more time spent together and the benefits of trying new foods with an open mind. Eight supporting subcategories formed the 2 subcategories. Participants relayed positive behavior change stating, "we have learned to cook independently" and "we try and use new recipes." Participant perceptions of increased cultural awareness and acceptance through trying different cuisines proved beneficial as well.

The fourth category was 'increased communication.' This category was formed by 2 subcategories. The first category, 'increased communication during mealtimes' was discussed as a positive effect on family dynamics; participants felt that conversation starter cards improved connections and communication. Additionally, participants felt more connected during mealtimes due to a decreased use of electronic devices. The second subcategory of 'increased communication amongst friends and family' led to an open line of communication. A participant went on to state that, "talking to parents can improve self-esteem and boost confidence." Eight supporting subcategories created the subcategories. Participants felt that this improved communication and could potentially stop bullying, increase trust, and decrease stress because of more time spent communicating together.

The fifth category was 'changed motivation.' This category was formed by 4 supporting subcategories. A participant felt that better eating choices were being made and this change was 
taking place because of the motivation to improve health. Likewise, participants felt that he/she was happier and happiness is contagious; expressing the motivation to spread happiness. Participants felt that he/she learned that TV doesn't matter and he/she are now motivated to get away from the TV and candy and prefer to do other activities that benefit health.

The sixth category was 'financial mindfulness.' This category included 3 supporting subcategories. Participants felt that when you are healthier (referring to being healthier after the iCook 4-H program), you are cheaper due to a decrease in insurance costs and taxes from health related issues. Participants also felt that he/she saves money because the family does not eat out as frequently due to enjoyment of cooking meals at home together. Similarly, participants felt that finances improved through creating shopping lists and budgeting funds to incorporate more fruits and vegetables.

The seventh and final category was 'increased appreciation for family members leading to a better understanding of one another.' Four supporting subcategories were found within this category. Participants relayed that increased youth dependence and trust leads to youth cooking dinner (by yourself), as well as an improved family member harmony leading to decreased stress.

To confirm accuracy of participant perceptions within the qualitative content analysis, word frequencies were created from the data templates for comparison (Table 7). These word frequencies were then compared to the participant perceptions of most important, most bonding and most bridging experiences. The prevalence of words found fit well with both data report templates and participant perceptions with most significant experiences through the percent prevalence of words in all comparison groups. A word cloud image is shown in Figure 5. 
Following REM sessions and analysis, each facilitator was interviewed with a series of seven questions to determine what worked well and consider areas for improvement for future dissemination. Session facilitators delivered positive session feedback and felt participants completed discussion appropriately considering the complexity of the theories being represented within REM. Family togetherness was a theme that seemed to me more impactful compared to the new experiences and games that were introduced to youth participants; this being an unexpected significance for facilitators and one not previously considered. Areas for improvement included the time allotment for each session; facilitators felt more time was needed to complete the feedback portion of the discussion. Additionally, word usage such as community capitals and REM could be modified or simplified for youth participants. Furthermore, capturing the REM sessions could take place prior to the 24-month post intervention time point to decrease any leading done by the facilitator to remind participants of all program activities.

\section{Discussion}

Adopting a framework to evaluate the effect of interventions and translation of sustainable action is needed to deploy with interventions addressing widespread chronic disease within the community setting (Harris, 2012; Kerner, 2005). To determine the appropriate framework for assisting in bridging the gap of research to practice, the study of dissemination and implementation science has proved beneficial. Several frameworks have been established as a result of implementation science that focus on evidence-based programs in community-based research, outlining methods that can be used to improve public health outcomes (Meyers, 2012). Some established frameworks addressing dissemination and implementation include the Interactive Systems Framework (ISF), the Availability, Responsiveness, Continuity (ARC) community intervention model, the Consolidated Framework for Implementation Research 
(CFIR), the Practical, Robust Implementation and Sustainability Model (PRISM), and the REAIM Framework (Meyers, 2012; Gaglio, 2013). Frameworks addressing the implementation and dissemination need to provide summaries of phases outlining quality implementation (Meyers, 2012). However, comprehensive methodologies of the evaluation tools that make up these frameworks are lacking for community based programing. Thus, REM acts as a feedback mechanism and evaluation tool, providing impact of program outcomes and participant perceptions. Additionally, it provides opportunities for researchers, community stakeholders, participants, and support staff to learn from these findings in order to make improvements in further dissemination. In this way, REM can act as a hands-on dissemination tool used as part of a preexisting implementation framework to fill the needed area of disseminated-communitybased research.

Although REM has been used within corporations (Darger, 2014), professional settings as part of a teaching curriculum (Wilansky, 2017) and within community programing in areas other than nutrition (Welborn, 2016), documentation of a stepwise REM process with detailed content analysis and word frequencies has not taken place. Using REM as part of the preexisting obesity prevention program's implementation and dissemination process assists to provide a method of determining various outcomes of the evidenced-based iCook 4-H program. Evidence supports that parents participating in physical activity with their child influences the child's amount of physical activity therefore increasing the potential to increase physical activity in both the child and the parent (Gurley-Calvez, 2010). Similarly, exploration into the food choices of children and parental influence shows that parents serve as role models for dietary habits, and at a young age, children learn to emulate feeding practices of parents (Savage, 2007). Thus, the results presented here provide innovation in the field of implementation science by using a REM 
evaluation tool with a dyad approach to better understand programmatic impacts regarding healthy lifestyles and dietary changes within an at risk youth population.

Understanding the effects of positive behavior change through an obesity prevention program like iCook 4-H, will better assist future research in determining ways to reduce obesity in youth in need of building skills and confidence. To understand program effects and outcomes, evaluation tools such as REM can be used to benefit participants, community members and researchers by providing visual imaging or story board through the ripple mapping of program impacts in an understandable way. Furthermore, using REM as a qualitative research evaluation tool gives a more telling and deeper story as compared to quantitative findings. Additional research is needed to definitively verify the use of REM as an appropriate evaluation tool within community based, obesity prevention research to better support implementation and dissemination. Replicating this stepwise REM process using other evidenced based programs within obesity prevention research can further document this tool's effectiveness as an impact evaluation tool. Furthermore, REM used within community, childhood obesity prevention programs would benefit with additional modifications to the current format and language used based on specific community demographics and program characteristics and objectives.

Providing youth-friendly terms in place of Ripple Effect Mapping and community capitals could assist in the clarity of instruction and implementation of the evaluation tool has on facilitators and participants. The generalization of REM findings for the program must be translated only to that direct community and location. In an effort to provide a detailed and documented stepwise process of REM, facilitators conducted each session with slight variations based on available resources of space, paper or whiteboard, usage of the data report templates, and writing utensils. But this is somewhat to be expected, as fidelity was not measured for this one REM session. 
Future use of this process should measure fidelity and variability of application. Lastly, facilitators having a full understanding of REM and the usage of the Community Capitals would improve the researchers' ability to determine and differentiate capitals within the categories during each session.

Due to the high prevalence of obesity and its associated risk factors, there is a growing body of literature that looks at how various childhood obesity prevention programs influence youth behaviors in hopes of reversing or preventing other obesity associated disease states. These programs have typically targeted a singular aspect or combination of diet, physical activity, nutrition education, communication and behavior change. However, there is limited research that evaluates when programs combine several of these aspects with a dyad approach to better influence positive lifestyle change for children such as iCook 4-H. Little research has been published looking at and evaluating these types of programs. This study combined the implementation of REM as an evaluation tool and the assessment of participant perceptions of iCook 4-H. Applying a tool such as REM can be used by researchers, community members and participants as an effective evaluation tool to demonstrate through a visual mapping image, the positive effects of obesity prevention programs to further the dissemination and implementation mileage, replicability and sustainably.

\section{Conclusion}

This research using qualitative data in a comprehensive, stepwise process is presented in a way that has not been previously reported. Detailed processes of impact evaluation tools that can be used with preexisting frameworks in dissemination and implementation science for community based programing are currently lacking. REM using $\mathrm{CCF}$ is an impact evaluation 
tool that has been found to effectively capture outcomes of this community-based research iCook 4-H program. Additionally, findings show youth obesity prevention programs such as the iCook 4-H program have the potential to positively affect one's self, family and community.

\section{Conflict of Interest}

The authors declare that they have no conflict of interest.

\section{Acknowledgements}

We thank the research participants who participated in this study and thank members of the Lifestyle Intervention Research Lab for their assistance and hard work (Rebecca Hagedorn, Allison Morris, Makenzie Barr, and Oluremi Famodu), as well as the iCook 4-H research team, note takers and facilitators that provided vital assistance during each Ripple Effect Mapping session. Additionally, we would like to thank Michelle Cesa and Jacqueline Quispe with help in the content analysis coding process that took place, as well as the support of Davis College of Agriculture, Natural Resources and Design at West Virginia University. 


\section{References}

1. Baker, B., and Gill, P. (2015) Ripple Effect Mapping Parts1-4: [Video files] UMaine Cooperative Extension YouTube. Supported by the National Institute of Food and Agriculture, U.S. Department of Agriculture, under award number 2012-68001-19605, iCook: A 4-H Program to Promote Culinary Skills and Family Meals for Obesity Prevention. Retrieved from https://www.youtube.com/watch?v=VRKBT-1YnAU or full set may be retrieved from: http://ucanr.edu/sites/Social_Capital_MultiState/Tools_for_Engagement___Evaluation/

2. Baker, B., and Johannes, E. (2013) Measuring social capital change using ripple mapping, Youth Programs as Builders of Social Capital: New Directions for Youth Development, Editors: M. Calvert, M. Emery, S. Kinsey, Number 138 (pp. 31-48) Publisher Jossey-Bass August 7, 2013, Hoboken, NJ: Wiley Periodicals, Inc)

3. Bandura, A. (2012). Social Cognitive Theory. Handbook of theories of Social Psychology. Sage Publications Inc.

4. Bauer, M. S., Damschroder, L., Hagedorn, H., Smith, J., \& Kilbourne, A. M. (December 16, 2015). An introduction to implementation science for the non-specialist. Bmc Psychology, 3, 1.

5. Darger, M. (January 01, 2014). Capturing the ripples from community-driven business retention and expasion programs. Journal of Extension, 52, 2.

6. Donaldson, A. B., Colby, S. E., Flanagan, S. M., Franzen-Castle, L. D., Kattelmann, K. K., Mathews, D., Merfeld, C. M., ... 2014 Food \& Nutrition Conference \& Expo FNCE Atlanta GA 20141018-20141021. (September 01, 2014). Cooking Behavior and SelfEfficacy of 9-10 Year Old Youth: iCook 4-H. Journal of the Academy of Nutrition and Dietetics, 114, 9.

7. Emery, M., Higgins, L., Chazdon, S., \& Hansen, D. (April 01, 2015). Using Ripple Effect Mapping to Evaluate Program Impact: Choosing or Combining the Methods That Work Best for You. Journal of Extension, 53, 2.

8. Emery, M., Fey, S., Flora, C. (2006) Using Community Capitals to Develop Assets for Positive Community Change. Illinois Institute for Rural Affairs.

9. Emery, M., \& Flora, C. B. (2006). Spiraling-up: Mapping community transformation with Community Capitals Framework. Community Development: Journal of the Community Development Society 37(1), 19-35.

10. Fey, Susan, Corry Bregendahl, and Cornelia Flora. (2006). "The Measure of Community Capitals through Research: A Study Conducted for the Claude Worthington Benedum Foundation by the North Central Regional Center for Rural Development." The Online Journal of Rural Research and Policy 1: 1-28.

11. Franzen-Castle L, Krehbiel M, White A, Mathews DR, Yerxa K, Colby S, Meade R, Kattelmann K, Kabala C, Olfert M, Flanagan S. Assessing effectiveness of the implementation of a 12-week curriculum for youth and adults: iCook 4-H. J. Nutr Educ Behav. 2014; 46: S104.

12. Gaglio, B., Shoup, J. A., \& Glasgow, R. E. (2013). The RE-AIM Framework: A Systematic Review of Use Over Time. American Journal of Public Health, 103(6), 3846. 
13. Gurley-Calvez, T., \& Higginbotham, A. (September 01, 2010). Childhood Obesity, Academic Achievement, and School Expenditures. Public Finance Review, 38, 5, 619.

14. Harris, J.R., Cheadle, A., Hannon P.A., et al. (2012). A Framework for Disseminating Evidence-Based Health Promotion Practices. Preventing Chronic Disease, 9:22.

15. Hsieh H.F., \& Shannon S.E. (2005). Three appraoches to qualitative content analysis. Qaul Health Res, 15(9):1277-88.

16. Kerner J, Rimer B, Emmons K. (2005). Introduction to the Special Section on Dissemination: Dissemination Research and Research Dissemination: How Can WE Close the Gap? Health Psychology, 24(5):443-446.

17. Kollock, D. H., Flage, L., Chazdon, S., Paine, N., \& Higgins, L. (October 01, 2012). Ripple Effect Mapping: A "Radiant" Way to Capture Program Impacts. Journal of Extension, 50, 5.

18. Lobo, Roanna, Petrich, Mark, \& Burns, Sharyn K. (2014). Supporting health promotion practitioners to undertake evaluation for program development. BioMed Central.

19. Mathews D, Franzen-Castele L, Kattelmann K, Colby S, Olfert M, White A. Use of a systematic 3-pronged evaluation to measure, monitor, and test fidelity of the 5-state icook 4-H program. FASEB J. 2015;29:S395.8.

20. Meyers, D. C., Durlak, J. A., \& Wandersman, A. (December 01, 2012). The Quality Implementation Framework: A Synthesis of Critical Steps in the Implementation Process. American Journal of Community Psychology, 50, 462-480.

21. Miller A, Franzen-Castle L, Aguirre T, Krehbiel M, Colby S, Kattelmann K, Olfert M, Mathews D, White A. Food-Related Behavior and Intake of Adult Main Meal Preparers of 9-10 Year-Old Children Participating in iCook 4-H: A Five-State Childhood Obesity Prevention Pilot Study. Appetite. 2016;101:163-170.

22. Nathaniel, K., \& Nathaniel, K.C. (2012). Contributions of youth engagement to the development of social capital through community mapping. Journal of Extension, 51(1).

23. National 4-H History Preservation Team. (2017). National 4-H History Preservation Program. Retrieved from http://4-hhistorypreservation.com/History/M-C-P/

24. Priest K, Kaufman E, Brunton K, Seibel M. Appreciative Inquiry: A Tool for Organizational, Programmatic, and Project-Focused Change. Journal Of Leadership Education 2013;12(1):18-33.

25. Rennekamp, R. A., \& Arnold, M. E. (June 01, 2009). What progress, program evaluation? Reflections on a quarter-century of extension evaluation practice. Journal of Extension, 47, 3.

26. Savage, J. S., Fisher, J. O., \& Birch, L. L. (January 01, 2007). Parental influence on eating behavior: conception to adolescence. The Journal of Law, Medicine \& Ethics: a Journal of the American Society of Law, Medicine \& Ethics, 35, 1, 22-34.

27. Sorenson AR, Kattelmann KK, Meendering JR, Kabala CM, Mathews DR, * Olfert MD, Colby SE, Franzen-Castle L, White AA. Assessment of physical activity in 9- to 10-year old children participating in a family-centered intervention. Topic Clin Nutr. 2015;30 (2): 159-166.

28. Thomas E, Magilvy J. (2011). Qualitative Rigor or Research Validity in Qualitative Research. Journal for Specialists In Pediatric Nursing, 16(2):151-155.

29. U.S. Department of Health and Human Services Centers for Disease Control and Prevention. Office of the Director, Office of Strategy and Innovation. Introduction to 
program evaluation for public health programs: a self-study guide. Atlanta, GA. Centers for disease Control and Prevention, 2011.

30. Wandersman, A., Duffy, J., Flaspohler, P., Noonan, R., Lubell, K., Stillman, L., Blachman, M., ... Saul, J. (January 01, 2008). Bridging the gap between prevention research and practice: the interactive systems framework for dissemination and implementation. American Journal of Community Psychology, 41, 3-4.

31. Wang, F., Wild, T. C., Kipp, W., Kuhle, S., \& Veugelers, P. J. (January 01, 2009). The influence of childhood obesity on the development of self-esteem. Health Reports, 20, 2 , 21-7.

32. Welborn, R., Downey, L., Dyk, P.H., Monroe, P.A., Tyler-Mackey, C., \& Worthy, S., L. (2016). "Turning the Tide on Poverty: Documenting Impacts Through Ripple Effect Mapping." Community Development, 47.3: 385-402.

33. Wilansky, J.A. (2006). "The Effects of Curriculum Mapping on the Instructional Practices of Professional Collaboration, Standards Alignment, and *assessment." Order No. 3205824 Dowling College, Ann Arbor: ProQuest.

34. Zhang, Y and Wildemuth, B.M. (2009). "Qualitative analysis of content," in Applications of Social Research methods to Questions in Information and Library Science, B. Wildemuth, Ed., Libraries Unlimited, Westport, Conn, USA. 


\section{TABLES}

Table 1. Ice Breaker iCook Questions

\begin{tabular}{|c|c|}
\hline Questions & Answers \\
\hline $\begin{array}{l}\text { Washing your cutting board after cutting } \\
\text { chicken before cutting lettuce is a good way } \\
\text { to prevent } \quad \text { ? }\end{array}$ & Cross-contamination \\
\hline $\begin{array}{l}\text { In order to set strong goals you want to make } \\
\text { sure they are SMART, which means that your } \\
\text { goals are }\end{array}$ & $\begin{array}{l}\text { Specific, Measurable, Attainable, Relevant, } \\
\text { Time-Oriented }\end{array}$ \\
\hline $\begin{array}{l}\text { According to MyPlate, how much of our plate } \\
\text { should be fruits and vegetables? }\end{array}$ & Half your plate \\
\hline $\begin{array}{l}\text { When choosing canned fruits, which would be } \\
\text { a healthier choice, fruits canned in fruit juice } \\
\text { or fruits canned in heavy syrup? }\end{array}$ & Fruits canned in fruit juice \\
\hline $\begin{array}{l}\text { MyPlate tells us we should use lean proteins. } \\
\text { What would be an example of this? }\end{array}$ & Black beans \\
\hline When should you stretch? & Before and after physical activity \\
\hline Stretching helps prevent & Injuries \\
\hline How long should you hold a stretch & $15-20$ seconds \\
\hline What would be a muscle building activity? & Raking leaves \\
\hline $\begin{array}{l}\text { The cooking technique that is done in a pan at } \\
\text { high temperatures in small amount of oil is } \\
\text { ? }\end{array}$ & Stir-frying \\
\hline $\begin{array}{l}\text { The type of knife used for small cutting jobs } \\
\text { like removing the leaves from strawberries is } \\
\text { ? }\end{array}$ & Paring knife \\
\hline $\begin{array}{l}\text { What should you look for on the ingredients } \\
\text { list of food labels to know if a grain is the } \\
\text { best choice? }\end{array}$ & $100 \%$ whole grain \\
\hline $\begin{array}{l}\text { Aerobic activity helps keep our hearts healthy } \\
\text { and raises our pulse. What did we measure to } \\
\text { see the effect different types exercise had on } \\
\text { our hearts? }\end{array}$ & Heart rate \\
\hline $\begin{array}{l}\text { What can be used at mealtime to encourage } \\
\text { talking }\end{array}$ & Conversation starter cards \\
\hline
\end{tabular}

Questions and corresponding answers to Ice Breaker Activity completed by dyads.

Table 2. Ripple Effect Mapping Explanation for Participants in the iCook program

"This session will give us a better understanding of your experience with the iCook program and how it impacted you individually and as a group and/or community. This map will be a tool for us to understand the effects this program has had on your families and in the community through a 'rippling effect.' This 'ripple effect' is like a pebble being dropped into a pond; one small pebble can make a large impact of ripples throughout a pond. Similarly, a 
singular program can make small and large impacts within a family and community by individuals passing on their new experiences and knowledge learned from the program to others."

\section{Table 3. Community Capital Descriptions}

Social: the connections and bonding between people and organizations that help make things happen and link new people together.

Natural: natural resources such as rivers, parks, outdoor recreation areas, farmlands, etc. Cultural: ideas and customs such as local traditions, art, music, ways of thinking, family customs, etc.

Human: the knowledge, skills, and abilities of people such as work skills, leadership ability, health and wellness of people, etc.

Political: access to power and the ability to affect change due to a title, one's leadership, or work position such as government officials.

Financial: the monetary resources available to invest including business, entrepreneurship, etc.

Built: infrastructures that support the community such as telecommunications roads, buildings, etc.

Descriptions of the seven community capitals founded within the Community Capital Framework.

Table 4. Ripple Effect Mapping Questions for iCook Participants

1. What are people doing differently as a result of the iCook program?

2. Who has benefited from the iCook program and how?

3. Are there changes in the way community groups and institutions do things as a result of the iCook program?

Table 5. Participant Identified Most Important, Most Bonding, Most Bridging Outcomes from iCook 4-H

\begin{tabular}{|l|l|l|}
\hline Most Important/Significant & Most Bonding & $\begin{array}{l}\text { Most Bridging with New } \\
\text { People }\end{array}$ \\
\hline Eating dinner earlier (TN) & $\begin{array}{l}\text { New experiences and eating } \\
\text { together (TN) }\end{array}$ & Exercise (TN) \\
\hline $\begin{array}{l}\text { Everyone having fun together } \\
\text { (TN) }\end{array}$ & $\begin{array}{l}\text { Trying new foods and } \\
\text { cooking together (TN) }\end{array}$ & $\begin{array}{l}\text { Playing together and what } \\
\text { you do together (TN) }\end{array}$ \\
\hline $\begin{array}{l}\text { Becoming more } \\
\text { healthy/active from the iCook } \\
\text { program (WV) }\end{array}$ & Cooking together (WV) & $\begin{array}{l}\text { Everyone playing together } \\
\text { and making more friends } \\
\text { (WV) }\end{array}$ \\
\hline $\begin{array}{l}\text { Everyone has fun together } \\
\text { (WV) }\end{array}$ & $\begin{array}{l}\text { Eating together and trying } \\
\text { new foods (WV) }\end{array}$ & $\begin{array}{l}\text { Playing together and what } \\
\text { you do together (WV) }\end{array}$ \\
\hline $\begin{array}{l}\text { ME and friends spend more } \\
\text { time together (SD) }\end{array}$ & $\begin{array}{l}\text { Being a coach for special } \\
\text { Olympics (SD) }\end{array}$ & $\begin{array}{l}\text { You have better } \\
\text { communication (SD) }\end{array}$ \\
\hline
\end{tabular}




\begin{tabular}{|l|l|l|}
\hline $\begin{array}{l}\text { iCook-because it made all of } \\
\text { those reactions, better } \\
\text { conversation at the table- } \\
\text { before we didn't have much } \\
\text { conversation (SD) }\end{array}$ & $\begin{array}{l}\text { Better conversations, cooking } \\
\text { for my family, being active } \\
\text { (SD) }\end{array}$ & $\begin{array}{l}\text { School, doing things in the } \\
\text { community (SD) }\end{array}$ \\
\hline $\begin{array}{l}\text { More family time and playing } \\
\text { more sports (NE) }\end{array}$ & $\begin{array}{l}\text { Health improves and you } \\
\text { have more energy (NE) }\end{array}$ & $\begin{array}{l}\text { Sharing experiences with } \\
\text { others and using new recipes } \\
\text { from class (NE) }\end{array}$ \\
\hline $\begin{array}{l}\text { Active people are living } \\
\text { longer inside and have less } \\
\text { medical issues; live longer } \\
\text { and meet more people (ME) }\end{array}$ & $\begin{array}{l}\text { People from community and } \\
\text { school are learning things } \\
\text { from each other and learning } \\
\text { new ways to do things (ME) }\end{array}$ & $\begin{array}{l}\text { People are more interactive } \\
\text { and play together (ME) }\end{array}$ \\
\hline $\begin{array}{l}\text { Family harmony and trying } \\
\text { new things together (ME) }\end{array}$ & $\begin{array}{l}\text { Bonding relationships by } \\
\text { eating together and using } \\
\text { conversation starters (ME) }\end{array}$ & $\begin{array}{l}\text { We are cooking more and } \\
\text { play together more outside } \\
\text { (ME) }\end{array}$ \\
\hline $\begin{array}{l}\text { Cooking for community and } \\
\text { child is cooking a lot on her } \\
\text { own (ME) }\end{array}$ & $\begin{array}{l}\text { Whole family is growing } \\
\text { together and learning more } \\
\text { about each other (ME) }\end{array}$ & $\begin{array}{l}\text { Open to try a variety of foods } \\
\text { from different cultures. This } \\
\text { helps us to be more open } \\
\text { about other cultures (ME) }\end{array}$ \\
\hline
\end{tabular}

Following the REM discussion, participants were asked to discuss the most important or significant comment recorded on the mapping medium, as well as the comment that lead to the most bonding and most bridging among people within their community.

\section{Table 6: Demographic Questionnaire Results}

\begin{tabular}{|c|l|}
\hline Youth Gender $(\mathrm{n}=35)$ & Percentage \% (N) \\
\hline Female & $48.6(17)$ \\
\hline Male & $51.4(18)$ \\
\hline Youth Race & \\
\hline Caucasian & $71.4(25)$ \\
\hline African American & $5.7(2)$ \\
\hline Hispanic & $17.1(6)$ \\
\hline White/Native American & $2.9(1)$ \\
\hline Asian & $0(0)$ \\
\hline Native American & $2.9(1)$ \\
\hline $\begin{array}{l}\text { Group Best Representing Child's Race }(\mathrm{n}= \\
\text { 35) }\end{array}$ & \\
\hline Caucasian & $77.1(27)$ \\
\hline African American & $5.7(2)$ \\
\hline Hispanic & $14.3(5)$ \\
\hline White/Native American & $2.9(1)$ \\
\hline Asian & $0(0)$ \\
\hline Native American & $0(0)$ \\
\hline Youth's Current Grade (n=35) & \\
\hline $5^{\text {th }}$ grade & $11.4(4)$ \\
\hline $6^{\text {th }}$ grade & $65.7(23)$ \\
\hline $7^{\text {th }}$ grade & $22.9(8)$ \\
\hline
\end{tabular}




\begin{tabular}{|l|l|}
\hline Youth's Age- Average (Standard Deviation) & $11.4(0.65)$ \\
\hline $\begin{array}{l}\text { Child's Weight- Average (standard } \\
\text { Deviation) }\end{array}$ & $102.3(29.3)$ \\
\hline $\begin{array}{l}\text { Youth's Height in Centimeters- Average } \\
\text { (standard deviation) }\end{array}$ & $59.02(3.91)$ \\
\hline
\end{tabular}

\begin{tabular}{|c|c|}
\hline Adult Race $(\mathrm{n}=35)$ & \\
\hline Caucasian & $71.4(25)$ \\
\hline African American & $5.7(2)$ \\
\hline Hispanic & $17.1(6)$ \\
\hline White/Native American & $2.9(1)$ \\
\hline Asian & $2.9(1)$ \\
\hline Native American & $0(0)$ \\
\hline \multicolumn{2}{|l|}{$\begin{array}{l}\text { Group Rest Representing Adult's Race ( } \mathrm{n}= \\
\text { 35) }\end{array}$} \\
\hline Caucasian & $71.4(25)$ \\
\hline African American & $5.7(2)$ \\
\hline Hispanic & $17.1(6)$ \\
\hline White/Native American & $2.9(1)$ \\
\hline Asian & $2.9(1)$ \\
\hline Native American & $0(0)$ \\
\hline $\begin{array}{l}\% \text { of Adult Participants within each state }(\mathrm{n}= \\
35)\end{array}$ & Percentage $\%(\mathrm{~N})$ \\
\hline WV & $20.0(7)$ \\
\hline SD & $20.0(7)$ \\
\hline $\mathrm{TN}$ & $14.3(5)$ \\
\hline $\mathrm{ME}$ & $28.6(10)$ \\
\hline $\mathrm{NE}$ & $17.1(6)$ \\
\hline \multicolumn{2}{|l|}{$\begin{array}{l}\text { Number of Children Identified by Adults } \\
(\mathrm{n}=35)\end{array}$} \\
\hline 1 child & $11.4(4)$ \\
\hline 2 children & $37.1(13)$ \\
\hline 3 children & $40.0(14)$ \\
\hline 4 children & $5.7(2)$ \\
\hline 5 children & $0(0)$ \\
\hline 6 children & $2.9(1)$ \\
\hline 7 children & $2.9(1)$ \\
\hline \multicolumn{2}{|l|}{ Adult Highest Education Level $(\mathrm{n}=35)$} \\
\hline Elementary & $8.6(3)$ \\
\hline High School & $17.1(6)$ \\
\hline Some College & $5.7(2)$ \\
\hline Associate's Degree & $8.6(3)$ \\
\hline Bachelor's Degree & $34.3(12)$ \\
\hline Graduate Degree & $17.1(6)$ \\
\hline Doctoral Degree & $5.7(2)$ \\
\hline No response & $2.9(1)$ \\
\hline \multicolumn{2}{|l|}{ Adult's Current Marital Status ( $\mathrm{n}=35)$} \\
\hline Married & $85.7(30)$ \\
\hline
\end{tabular}




\begin{tabular}{|l|l|}
\hline \multicolumn{1}{|c|}{ Committed Relationship } & $8.6(3)$ \\
\hline Single & $5.7(2)$ \\
\hline \multicolumn{1}{|c|}{ Divorced } & $0(0)$ \\
\hline $\begin{array}{l}\text { Total individuals in household- Average } \\
\text { (standard deviation) }\end{array}$ & $4.4(1.3)$ \\
\hline $\begin{array}{l}\text { Total adults living in household- Average } \\
\text { (standard deviation) }\end{array}$ & $2.1(0.5)$ \\
\hline $\begin{array}{l}\text { Total number of children living in household } \\
\text { under 18 years of age- Average (standard } \\
\text { deviation) }\end{array}$ & $2.3(1.0)$ \\
\hline Adult's Age- Average (standard deviation) & $41.9(6.3)$ \\
\hline $\begin{array}{l}\text { Adult's Weight- Average (standard } \\
\text { deviation) }\end{array}$ & $157.8(35.1)$ \\
\hline $\begin{array}{l}\text { Adult's Height in Centimeters- Average } \\
\text { (standard deviation) }\end{array}$ & $64.8(2.9)$ \\
\hline
\end{tabular}

Table 7: REM Word Frequencies

\begin{tabular}{|l|l|}
\hline $\begin{array}{l}\text { Word Frequencies (WF) Groupings } \\
\text { (n=1750) }\end{array}$ & $\begin{array}{l}\text { \% of Total } \\
\text { Words/Groups }\end{array}$ \\
\hline Most Significant WF Grouping & \\
\hline More/frequently & 7.31 \\
\hline Family/friends/relatives/significant others & 7.20 \\
\hline New & 6.45 \\
\hline Benefit/better/improve & 6.40 \\
\hline People/members/others/groups/society/staff/someone & \\
\hline $\begin{array}{l}\text { Community/center/organization/businesses/recycling } \\
\text { company/committee/extension/senior center/companies/farmers and farmer's } \\
\text { markets/public littering }\end{array}$ & 2.91 \\
\hline Cooking/cook & 2.74 \\
\hline Kids/child/youth/girls/boys & \\
\hline Parents/siblings/brother/daughter/mom/aunts & 2.62 \\
\hline Trying & 2.57 \\
\hline Healthier/healthy/health & 2.51 \\
\hline Supporting WF Grouping & 2.40 \\
\hline $\begin{array}{l}\text { Exercise/fit/sporting teams/gym/sports/fit/ athletic/YMCA/physical activity } \\
\text { (such as yoga, running, ice skating, special Olympics, football, bike } \\
\text { riding)/fitness/games }\end{array}$ & 2.17 \\
\hline Eating/eat & 1.94 \\
\hline School/students/teacher(s)/class/gym teacher & \\
\hline Foods/potluck & 1.82 \\
\hline Active/playing/physically active & 1.65 \\
\hline
\end{tabular}

Top 15 categories/groupings have been included within this table. These word groups were compared to the participant perceptions of most important, most bonding and most bridging experiences (Table 5). The prevalence of words found fit well with both data report templates and participant perceptions with most significant experiences through the percent prevalence of words in all comparison groups. 


\section{FIGURES}

Figure 1: Ripple Effect Mapping Checklist

\begin{tabular}{|c|c|c|c|}
\hline 1. & \multicolumn{3}{|l|}{ Prior to Session } \\
\hline a. & \multicolumn{3}{|c|}{ Select mapping session location/venue/time/date of session } \\
\hline b. & \multicolumn{3}{|c|}{ Determine number of participants } \\
\hline C. & \multicolumn{3}{|c|}{ Session leader-complete necessary training prior to REM session } \\
\hline d. & \multicolumn{3}{|c|}{$\begin{array}{l}\text { Call/email/text participants for reminder } 1 \text { week and again } 2 \text { days before } \\
\text { scheduled meeting }\end{array}$} \\
\hline 2. & \multicolumn{3}{|l|}{ Day of Session } \\
\hline & \multicolumn{3}{|c|}{ Arrange room layout into half-circle seating for participants } \\
\hline & \multicolumn{3}{|c|}{$\begin{array}{l}\text { Assemble with team (facilitator and note takers) 20-30 minutes } \\
N \text { session format }\end{array}$} \\
\hline \multirow[t]{5}{*}{ C. } & \multicolumn{3}{|l|}{ Items needed: } \\
\hline & - Consent Forms & $\begin{array}{l}\text { - Whiteboard, } \\
\text { chalkboard, or paper }\end{array}$ & $\begin{array}{l}\text {-Community capitals } \\
\text { handouts for } \\
\text { participants and labels } \\
\text { for REMap }\end{array}$ \\
\hline & $\begin{array}{l}\text { - Demographic } \\
\text { Questionnaires }\end{array}$ & - Markers or chalk & $\begin{array}{l}\text { - Paper and pens for } \\
\text { participants }\end{array}$ \\
\hline & - Media Release Forms & - Computers/ laptops & - Gift Cards/ incentives \\
\hline & - Post-it notes & - Extra paper and tape & $\begin{array}{l}\text { - Video camera/ audio } \\
\text { recorder/ camera } \\
\text { (smartphone) }\end{array}$ \\
\hline
\end{tabular}

d. Arrange Community Capitals around map area, post-it notes for the ice breaker Q\&A, and extra sheets of paper for the brainstorming activity

\section{Participant Arrival at Session/ During Session}

a. Have participants fill out demographics questionnaire, consent form, and media release form

b. Pass out the community capitals handouts (colored and list format)

c. Introduction of session and explanation of format and what will take pace

d. Ice Breaker Q\&A

e. Brainstorming Activity

f. Discussion takes place/ REMap is formed

g. Record/ videotape session

Ripple Questions:

1. What are people doing differently as a result of the iCook program? 


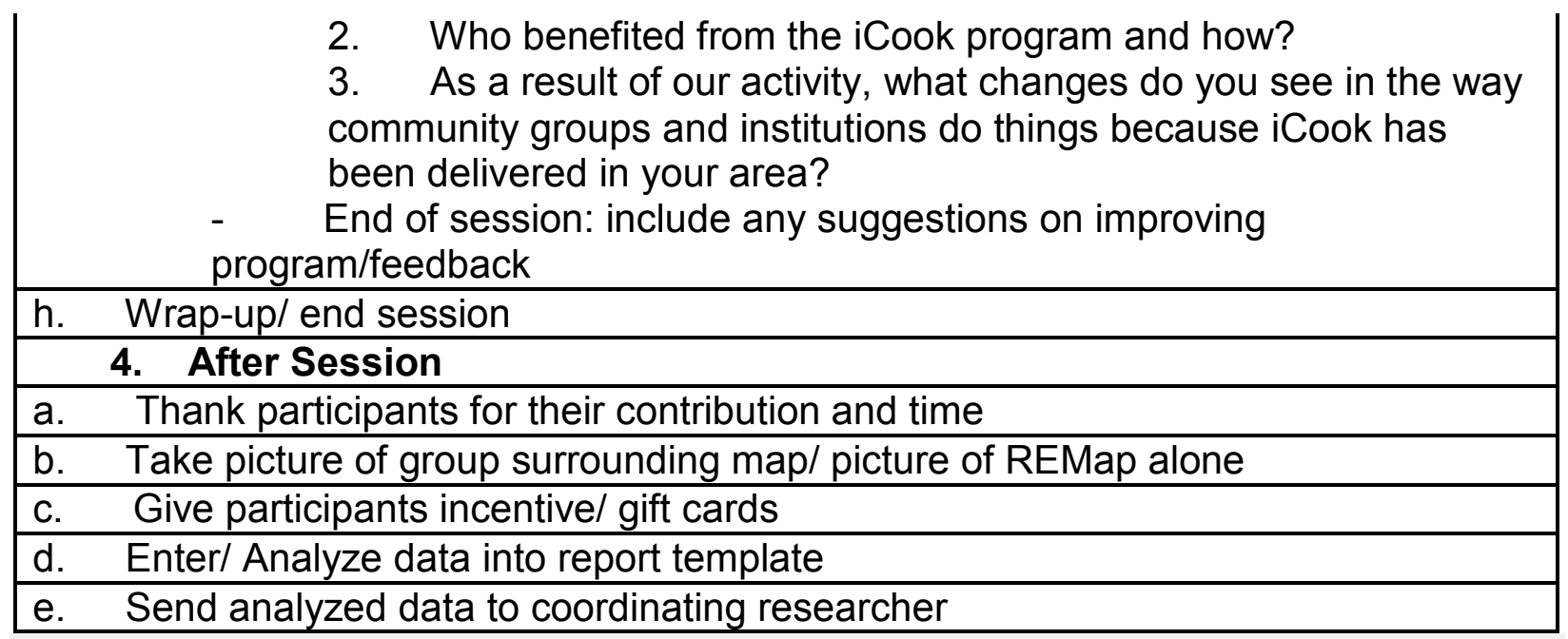

\section{Figure 2. Sample Mapping Template}

Cultural

\section{Natural}

Social

Built

iCook

Human

Financial

Political 
Figure 3. Finished Sample of REM Image

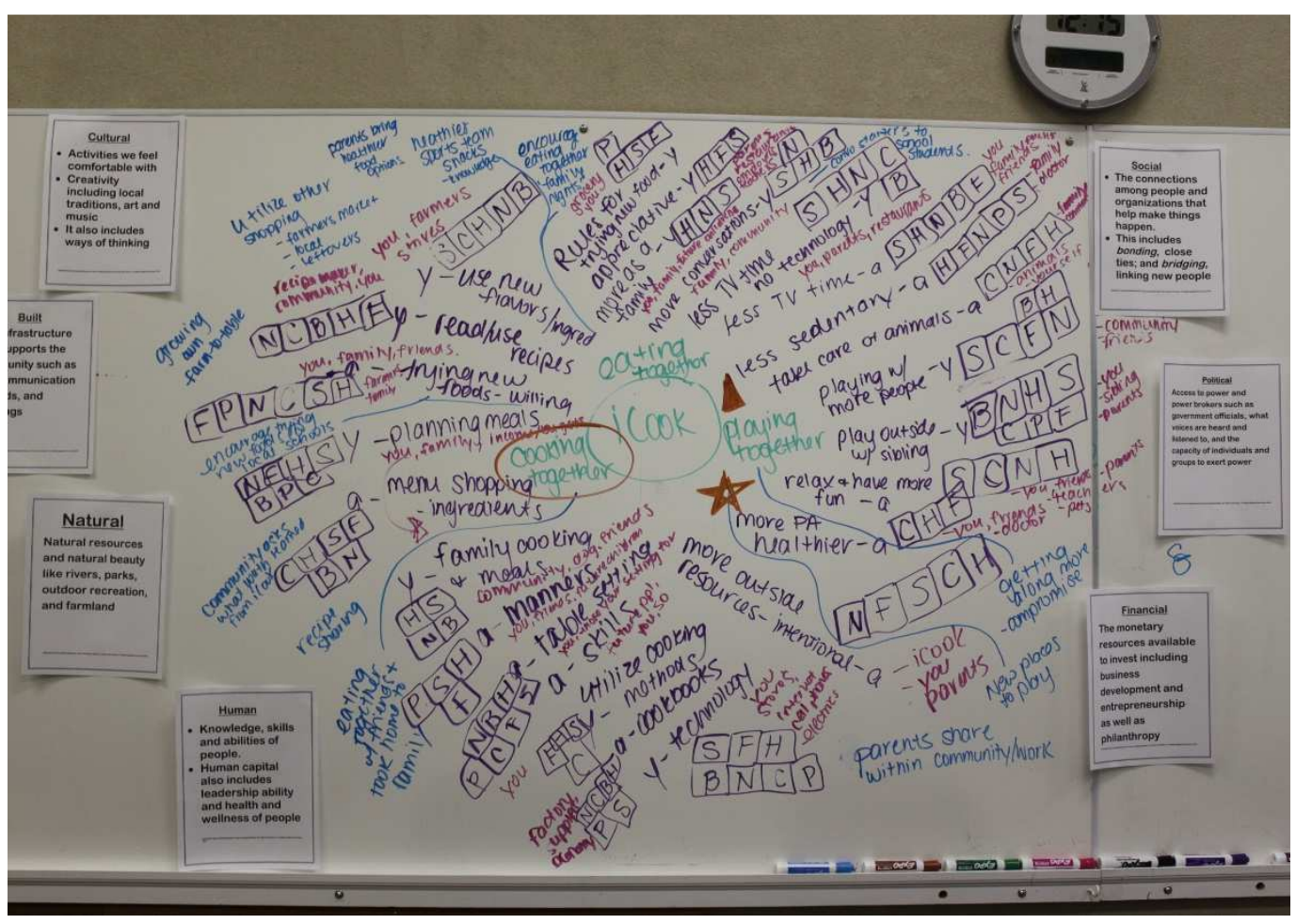

Figure 4. Theme, categories, and subcategories of Participant Perceptions with the iCook $\underline{\text { Program }}$ 


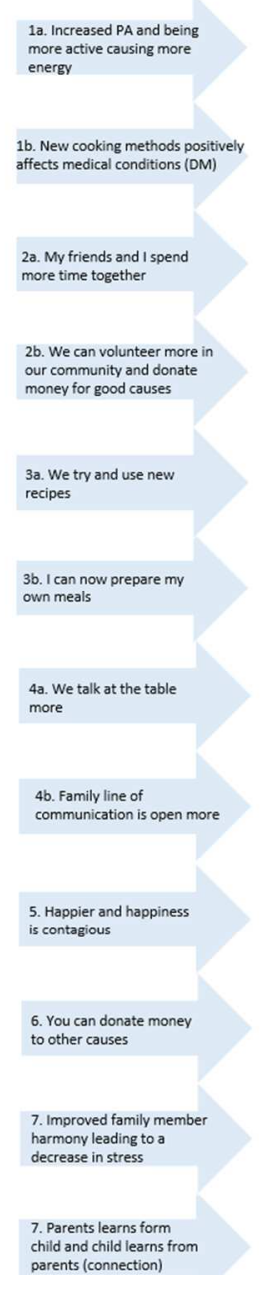

1a. Increased PA and being more active causing more

1b. New cooking methods positively affects medical conditions (DM)

Theme: Learning new skills together through trying new things (cooking, eating and playing) leads to positive individual family and community change.

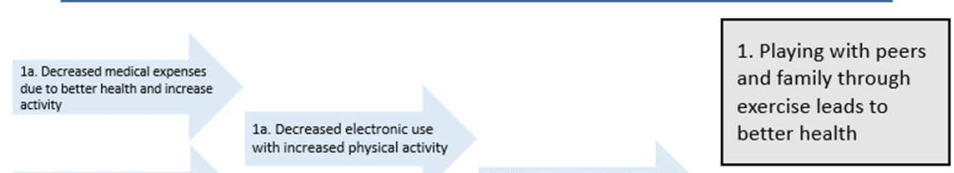

10. Cooking with more fruits \& veggies, less salt and using more
spices (affects health positively)

2a. I now influence other friends participate and try new things

2b. We are now role models at the community center for the kids with increased physical activity

\section{1a. More fit, healthier, sleeping} better and laughing more

2b. More communication at homes can stop bullying and the schools benefit from it

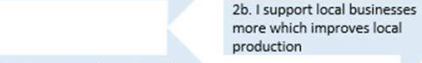

2a. We can teach our friend communication skills

3a. Increased friendships and a. Increased friendships and
encourage friends to learn new encourage frients
games to play

2b. We can create more jobs by spending more time in the more which improves local prodent

3a. I am a role model now in the community because peo see me trving new exercises

3b. I now look at food labels more 4a. No electronics now while
eating

4b. Family now hears what is going on throughout your day-
can help you if you need it

5. Learned that TV doesn't matter and will be motivated
to get away from the TV more

6. Family finances improve because we now use shopping
lists to save money

7. Taking better care of $m y$ pets and animals now community

\section{3a. We try new and different flavors and spices}

\section{3b. We have learned to cook} independently

\section{4a. We now use conversation starters during dinner and}

4b. Enhanced social skills enhances self-esteem, and boosts confidence

5. Looking into the future sol am healthier and a better cook 3b. More cultural awareness and
acceptance by trying different cuisines

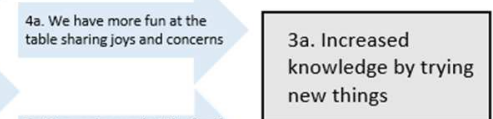

4b. We can learn what the family thinks is fun and play together more

5. I make better eating choices
(because I know it will effect my health)

6. We are now financially mindful to include fruits \& veggies

7. Increased child dependence dinner (appreciation expresse

Supporting Subcategories 3b. Increased Knowledge through education and experience

4a. Increased mealtimes

4b. Increased communication amongst friends and family

Subcategories communication during

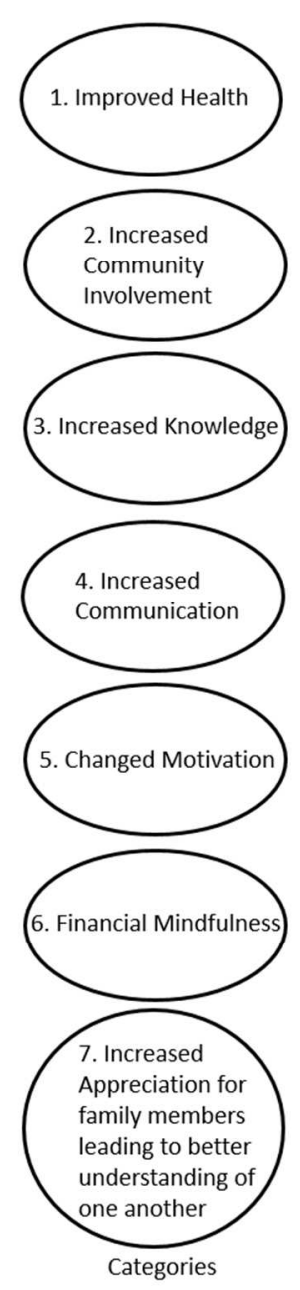




\section{Figure 5. Word Cloud from Word Frequencies Data}

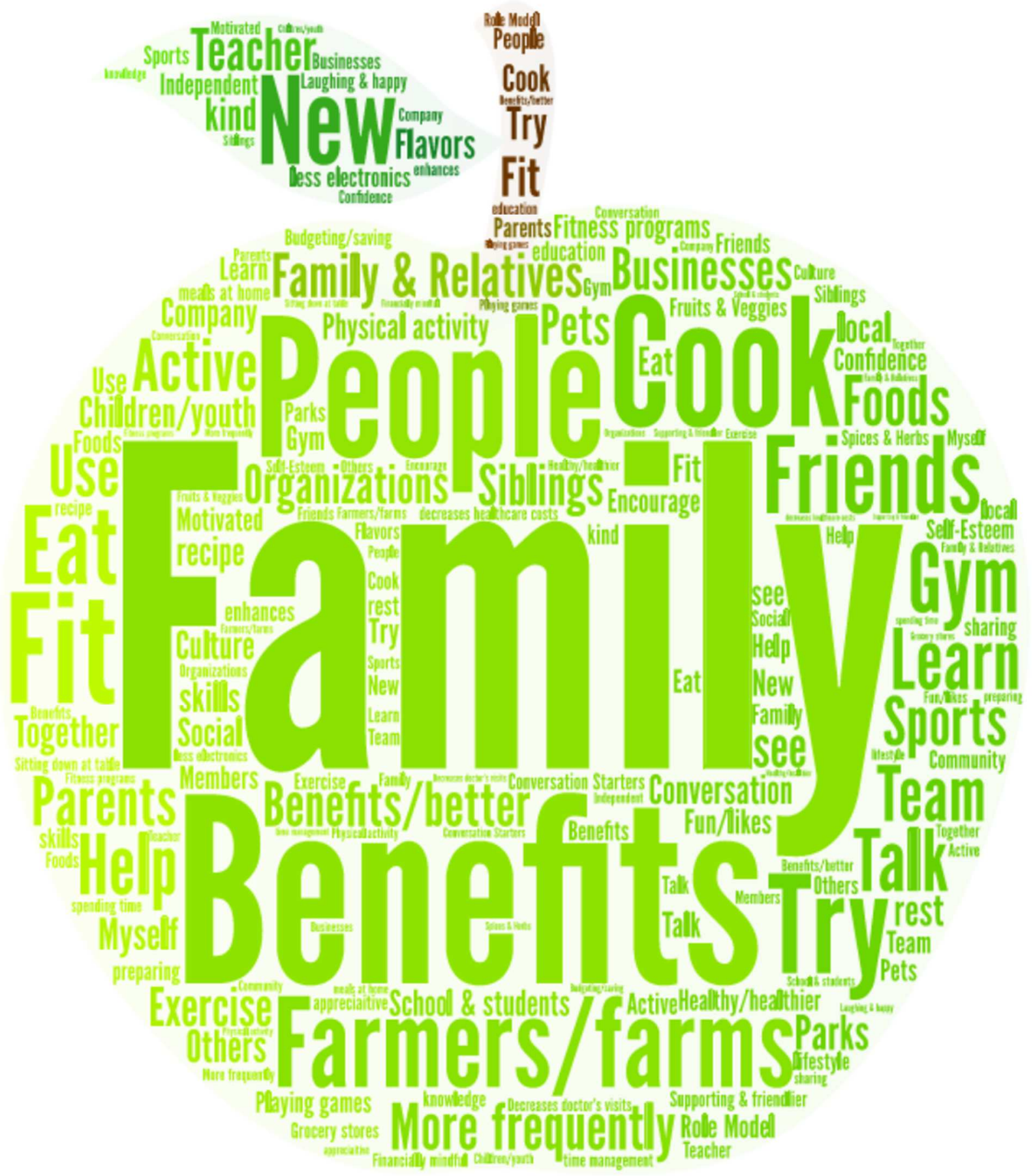




\section{APPENDICES}

\section{APPENDIX A}

\section{References}

1. Baker, B., Calvert, M., Emery, M., Enfield, R., \& Williams, B. (2011). Mapping the impact of youth on community development: What are we learning? [PowerPoint slides].

2. Baker, B., Jobannes, E. (2013). Measuring social capital change using ripple mapping. New Directions for Youth Development. Wiley Periodicals, INC. DOI: 10.1002/yd.20056

3. Bandura, A. (2012). Social Cognitive Theory. Handbook of theories of Social Psychology. Sage Publications Inc.

4. Bauer, M., Damschroder, L., Hagedorn, H., Smith, J., Kilbourne, A. (2015). An introduction to implementation science for the non-specialist. BMC Psychol, 13:32.

5. Brandt, M. (2004). Obese parents increase kids' risk of being overweight. Stanford Report.

6. Center for Disease Control and Prevention. (2012). Adult Overweight and Obesity. Centers for Disease Control and Prevention.

7. Center for Disease Control and Prevention (2015). Childhood Obesity Facts. Centers for Disease Control and Prevention.

8. Child Trends. (2007) Why conduct a program evaluation. Research to Results. 31.

9. Community Capitals (CC). (2015). Department of Sociology, Iowa State University. N.p., n.d. Retrieved from: http://www.soc.iastate.edu/staff/cflora/ncrcrd/capitals.html

10. Darger, M. (2014). Capturing the ripples from community-driven business retention and expansion programs. Journal of Extension 52(2).

11. Emery, M., S. Fey, and C.B. Flora, (2006). "Using Community Capitals to Build Assets for Positive Community Change." CD Practice 13.

12. Emery, M., Higgins, L., Chazdon, S., Hansen, D. (2015) Using ripple effect mapping to evaluate program impact: choosing or combining the methods that work best for you. Journal of Extension 53(2).

13. Emery, M., \& Flora, C. B. (2006). Spiraling-up: Mapping community transformation with community capitals framework. Community Development: Journal of the Community Development Society 37(1), 19-35.

14. Emery, M., \& Flora, C. B. (2006). Spiraling-up: Mapping community transformation with community capitals framework. Community Development: Journal of the Community Development Society 37(1), 19-35.

15. Emery, M., Fey, S., Flora, C. (2006) Using Community Capitals to Develop Assets for Positive Community Change. Illinois Institute for Rural Affairs.

16. Fey, S., C. Bregendahl, and C.B. Flora, (2006). "The Measurement of Community Capitals through Research: A Study Conducted for the Claude Worthington Benedum Foundation by the North Central Regional Center for Rural Development." Online Journal of Rural Research and Policy 1-28.

17. Goldstein, N. (2015). The Program Manager's Guide to Evaluation. Print.

18. Hammond, R. A., \& Levine, R. (2010). The economic impact of obesity in the United States. Diabetes, Metabolic Syndrome and Obesity: Targets and Therapy, 3, 285-295. 
19. Hansen Kollock, D. A., Flage, L., Chazdon, S., Paine, N., \& Higgins, L. (2012). Ripple effect mapping: A "radiant" way to capture program impacts. Journal of Extension, 50(5).

20. Harvard School of Public Health Prevention Research Center (HPRC). (2015). Retrieved from http://www.hsph.harvard.edu/prc/.

21. Linnell, D. (2014). Process Evaluation vs. Outcome Evaluation. Third Sector New England. Retrieved December 6, 2015, from http://tsne.org/process-evaluation-vsoutcome-evaluation

22. Olfert, M., Famodu, O, Ed. (2015, May 18). Lifestyle Intervention, Olfert Research Lab: West Virginia University. Retrieved from http://melissa-olfert.davis.wvu.edu/researchprojects.

23. Meyers, D.C., Durlak, J.A., Wandersman, A. (2012). The quality implementation framework: a synthesis of critical steps in the implementation process. Am J Community Psychol, 50(3-4): 462-480.

24. Nathaniel, K., \& Kinsey, S. (2013). Contributions of youth engagement to the development of social capital through community mapping. Journal of Extension 51(1).

25. Priest K., Kaufman E., Brunton K., Seibel M. (2013). Appreciative Inquiry: A Tool for Organizational, Programmatic, and Project-Focused Change. Journal Of Leadership Education,12(1):18-33.

26. Rennekamp, R., \& Arnold, M. (2009). What Progress, Program Evaluation? Reflections on a Quarter-Century of Extension Evaluation Practice. Journal of Extension, 47(3).

27. Rennekamp, R., \& Arnold, M. (2009). What progress, program evaluation? Reflections on a quarter-century of Extension evaluation practice. Journal of Extension, 47(3).

28. Wang, Y., Wu, Y., Wilson, R., Bleich, S., Cheskin, L., Weston, C., . . Segal, J. (2013). Childhood Obesity Prevention Programs: Comparative Effectiveness Review and MetaAnalysis.

29. Welsby, D., Nguyen, B., O’Hara, B.J., Innes-Hughes, C., Bauman, A., Hardy, L.L. (2014). Process evaluation of an up-scaled community based child obesity treatment program: NSW Go4Fun. BMC Public Health, 10;14:140.

30. W.K. Kellogg Foundation. (2004). Using Logic Models to Bring Together Planning, Evaluation, and Action Logic Model Development Guide. 


\section{APPENDIX B}

\section{Ripple Effect Mapping Toolkit}

Why Ripple Effect Mapping?

To investigate participant attitudes, perceptions and beliefs after completing the iCook program

$>$ To collect participant perceptions of positive and negative outcomes and changes that resulted from the iCook program at the individual and community level

To describe in a map, the effect of the iCook program collectively with youth/adult pairs

Steps to Implementing Ripple Effect Mapping Session for iCook Research Intervention

Participants (August 2013-December 2015).....

\section{Appendix Attachments:}

1. Checklist

2. 7 Community Capital Descriptions for REMap

3. 2 Community Capitals Handouts for Participants (colored and list format)

4. Demographic Questionnaire

5. Data Template (this form is attached separately)

\section{Prior To Session}

Select mapping session location/venue/date/time of session

$\downarrow$ Recruit participants to attend session

- Minimum 3 dyads and no more than 6 per session (12 total people)

- Schedule additional sessions if group exceeds 6 dyads (12 participants)

- Time allotted for session should be between 1.5 to 2 hours

Session leader- complete training before ripple effect mapping session

- Trainings includes:

- Viewing video overview of Ripple Effect Mapping (REM)

https://youtu.be/4ZFPFGhF-SA

https://youtu.be/kaVqfar-deg

https://youtu.be/cqudamxvPXc

https://youtu.be/wG9LaULcs70

- The above links are subject to change and if updated versions are created these will be sent to you as well

Session leader- call/email/text participant 1 week -2 days prior to REM date

2. Day of Ripple Effect Mapping Session

* The layout of the room is very important; horseshoe or half-circle seating is usually best so participants can have optimal interaction between one another

$\$$ Debrief with team 20-30 minutes prior to review session format (session leader, note taker(s), other collaborators)

* Items needed for session are as follows:

1. Demographics questionnaires

- Filled out by parent/guardian

2. State consent forms

3. Media release forms

4. Video recorder/camera (or smartphone)/audio recorder 
- This is specifically requested in order to watch the ripple effect map evolve from the beginning stages of 3 main themes surrounding iCook, to latter stages of relationships among capitals. This will also be used to collect voice comments and make connections between individuals within the session (IRB approval for $W V$, TN and SD).

- Video recording will aid in connecting comments to youth (Y) or adults (A)

- Currently states collecting video/audio of the mapping process are WV,TN, and $S D$.......unsure of $N E$ and $M E$ video/audiotaping status

- Camera or smartphone at the end of the session is needed to take a still shot picture of participants surrounding the map, as well as an image of the REMap picture alone

5. Whiteboard/chalkboard/or combination of papers for drawing map

6. Markers/chalk for drawing map

- 4 different colors for the map are needed. Each 'ring' will have its own marker/chalk color. The session leader should draw lines to tie the idea of a participant to a specific comment, connecting each stage of the ring along the way.

7. Computer(s)/laptops for note taker during discussion

- It is recommended to have multiple note takers if video recording is absent or participant group is large (1 note taker with video/audio recorder)

8. Handout of the Community Capitals for each participant and Community Capitals colored graphic (see appendix for handout)

9. Community Capital Labels of seven capitals to surround the outer edge of REMap

- These 7 capitals should be placed around the map area prior to participant arrival

- Second item in the appendix

10. Gift cards

- Incentives for participant attendance (total \$50: youth \$25 and adult \$25)

11. Paper and pens for participants

- This is optional and should be an individual leader decision

- Benefit: participants can jot down thoughts so comments are not forgotten during brainstorming activity; however could be a distraction in that the child participant can focus on doodling rather than discussion.

12. Post-it Notes (2 different colors) This is for the ice breaker activity. The ice breaker $Q \& A$ should be written on sticky notes prior to session: see full instructions below

13. Extra sheets of paper \& tape

- This will be used for the brainstorming activity. Instructions for this activity can be found in the session breakdown below. This activity will have the participants list positive impacts of the iCook program and various activities that participants liked best.

\section{Preparation of REMapping Area}

* Have the Community Capital Labels surrounding the map area put up on whiteboard/chalk board/or designated wall area prior to participants showing up.

- These 7 capital labels can be found in the appendix section.

* Also have pen and paper, the community capitals colored graphic and the community capitals list format handout placed on tables.

- These handouts can also be found in the appendix section.

* Setup for ICE BREAKER Q\&A: write each individual question (which can be found in the 'Arrival at REM Session') on a post-it note. Choose a different color post-it note to write the answers to these questions on. 
- Place the questions in an ordered manor along the walls in only one color of post-it notes, such as light blue. Place the answers in a jumbled group on a separate portion of the wall in a different color of post-it notes, such as light green. (Questions and answers can also be printed and taped to the wall instead of using post-it notes.) A full list of answer choices with some wrong answers mixed can be found in the below section.

- During activity: Ask class participants to place the answers under the appropriate questions.

\& 2 pieces of paper should be set up on the wall next to the map as well for the session leader to write down the different topic areas that are discussed throughout. These 2 papers will be used during the brainstorming activity and feedback section. The instructions for this activity can be found in the 'Arrival at REM Session' section and 'REMap Breakdown'.

\section{Items to Remember Throughout REMap Session:}

Remember to be flexible and follow the discussion/adjust when needed

* Coordinate with the note taker; states in which video recording is not taking place will need to take exceptional care in documenting every aspect of session

- NOTE TAKER: Special attention and documentation should be placed on labeling the type of comment made during session: youth (Y), adult (A)

- Other focus includes: take notes on group dynamics, interactions, nonverbal signs, tones of voice and feelings expressed (Move to beginning)

Directions for Leader: During the session, make sure to use a different color marker or piece of chalk for each ring and 'ripple' created; draw lines connecting each thought of a participant to a capital and mark initials of the capitals in boxes by the comments of the participants (i.e.

$\mathbf{N}=$ Natural, $\mathbf{C}=$ Cultural, $\mathbf{H}=$ Human, $\mathrm{S}=$ Social, $\mathbf{P}=$ =political, $\mathbf{F}=$ Financial, $\mathrm{B}=$ Built $)$. Remember to draw lines to tie each comment to the appropriate capital so visual connections can be made.

- The detailed descriptions of these capitals can be found in the training video, as well as in the appendix section.

- Choose 3-4 areas to concentrate on (eating, cooking, talking and playing together); these themes will be focused on in the first ring around the iCook center.

- Read the question and repeat it for each of the 3-4 important themes from the list (cooking, eating, communicating, and playing together). Remember to pay attention to the note taker and participants for pace of questioning or stop and ask for clarity as necessary.

* After session is completed and participants have left, the session leader and not taker should begin recording data immediately. Record the time it takes for data to be entered into the sample template.

○ Record the session leader and note taker names on template as well.

\section{Arrival At REM Session:}

\section{Welcome Attendees:}

- Session leader welcomes attendees and identifies pertinent individuals in the room

* Have participants fill out the Consent Forms, Media Release Forms and Demographic Questionnaires

* Explain the purpose of the session and what will take place over the next 1.5-2 hours

- Sample explanation of REMap: "This session will give us a better understanding of your experience with the iCook program and how it impacted you individually and as a group and/or community. This map will be a tool for us to understand the effects this program has had on your families and in the community through a 'rippling effect.' This 'ripple effect' is like a pebble being 
dropped into a pond; one small pebble can make a large impact of ripples throughout a pond. Similarly, a singular program can make small and large impacts within a family and community by individuals passing on their new experiences and knowledge learned from the program to others."

Give explanation of each capital that is framing the map area. These explanations can be found in the session leader training video, as well as community capitals handout in the appendix section

* Ice Breaker: Lead Q\&A ice breaker so participants are relaxed and more comfortable with participating (some participants will be more comfortable than others speaking in a group setting)

- Q\&A ice breaker will include a game in which the participants will match answers to questions that are listed below. These question and answers are over Questions and Answers different activities the participants completed over the course of the program.

- Q: Washing your cutting board after cutting chicken before cutting lettuce is a good way to prevent ? A: Cross-contamination

- Q: In order to set strong goals you want to make sure they are SMART, which means that your goals are_? A: Specific, Measurable, Attainable, Relevant, Time-Oriented

- Q: According to MyPlate, how much of our plate should be fruits and vegetables? A: Half your plate

- Q: When choosing canned fruits, which would be a healthier choice, fruits canned in fruit juice or fruits canned in heavy syrup? A: Fruits canned in fruit juice

- Q: MyPlate tells us we should use lean proteins. What would be an example of this?A: Black beans

- Q: When should you stretch? A: Before and after physical activity.

- Q: Stretching helps prevent ? A: Injuries

- Q: How long should you hold a stretch? A: 15-20 seconds

- Q: What would be a muscle building activity? A: Raking leaves

- Q: The cooking technique that is done in a pan at high temperatures in small amount of oil is ? A: Stir-frying

- Q: The type of knife used for small cutting jobs like removing the leaves from strawberries is ? A: Paring knife

- Q: What should you look for on the ingredients list of food labels to know if a grain is the best choice? A: $100 \%$ whole grain

- Q: Aerobic activity helps keep our hearts healthy and raises our pulse. What did we measure to see the effect different types exercise had on our hearts? A: Heart rate

- Q: What can be used at mealtime to encourage talking? A: Conversation starter cards

- Have participants arrange the post-it answers under the appropriate post-it questions.

These questions should be placed on a wall close to the REMap area

- Review the answers as a class (this is more geared to the youth participants)

- Leader can choose 5 main themes from the Q\&A ice breaker to dialogue with participants

Moving On- Leader is to dialogue with participants into the iCook program memory lane by saying:

"Today we are going to review everything we have learned from iCook and have fun doing it!"

"First, let's think about the set activity we just completed, where you took a walk through each of the previous sessions revisiting what we did together, for example:"

- We can now answer questions about correctly using knives,

- Being safe around hot plates or ovens,

- Remembering food and cutting board safety, 
- Practicing how to set and achieve a goal,

- Being more exact about choosing foods that are low in fat and sugar by reading labels when shopping or eating out

- Trying out fun ways to get more exercise, and

- Having conversations around the dinner table.

-Wrap up the ice breaker activities with any additional comments to add and move on to brainstorming activity

Brainstorming Activity: participants pair up and interview each other about the following:

- Question 1: What are ways in which the iCook program has positively affected you (personally), your family and/or your community?

- Question 2: What activities during each session did you like the best?

- What is your favorite memory of cooking together

- What is your favorite memory of eating together

- What is your favorite memory of playing together

- The participants' pen and paper may be useful during this portion so he or she can write down a list of their favorite activities and ways in which those activities lead to positive impacts

- Once the session leader has given the paired individuals adequate time, bring entire group back together. Write down participants favorite things on the sheets of paper off from the map area. These sheets should be next to the REMap so it is close for reference.

After favorite activities are copied to the separate sheets of paper, the discussion can begin; NOTE: leader should first explain to the group that we encourage the youth participants to comment first on each question, with the adults commenting after youth ideas are stated.

○ At this point there should be 3-4 broad themes: Cooking together, Eating together, Talking together, and Playing together......

\section{REMap Breakdown:}

\section{Items for Leader to Remember:}

- Use a different color for each ring; draw lines connecting participant thoughts with the capitals, as well as with the same thoughts between ripples.

- For example: If a participant states that one of his or her favorite activities was practicing how to set and reach a goal in the first ring, this topic should also be discussed in the second ring and question. Because of this, this topic should be connected by drawing a line to connect ring one to ring two and so on.

- Mark initials of the capitals in boxes by the phrases of the participants, and draw lines to tie them to the appropriate capital label (Pause for note taker if more time if needed).

- Read the question and repeat it for each of the 3-4 important themes from the list (cooking, eating, communicating, and playing together). Remember to pay attention to the note taker and participants for pace of questioning or stop and ask for clarity as necessary.

- Choose 3-4 areas to concentrate on (eating, cooking, talking and playing together); these themes should be found in the first ring around the iCook center and should be documented in the same color of marker.

\section{The $1^{\text {st }}$ question and ring includes:}


- What are people doing differently as a result of $?$

- Take each topic (cooking, eating and being active together) which were from the favorite activities listed on the separate sheet of paper and these will be the topics of reference for the first ring.

- Once every participant has had a chance to comment, the session leader should then ask the group what capital is related to each comment. A line will be drawn to each capital and comment in the same color marker. Each comment should have a square next to it with the letter of the capital inside as well (i.e. $N=$ Natural, $\boldsymbol{C}=$ Cultural, $\boldsymbol{H}=\mathbf{H u m a n}$, $\boldsymbol{S}=$ Social, $\boldsymbol{P}=$ political, $\boldsymbol{F}=$ Financial, $\boldsymbol{B}=$ Built).

- Once this is completed the session leader can move on to the $2^{\text {nd }}$ ring. The comments for this ring will surround the first ring and be connected with a different color maker.

\section{The $2^{\text {nd }}$ ring question is as follows:}

-Who benefited from the iCook program and how?

- This overall question should be addressed to each individual comment.

- Connect each comment in the second ring to a capital as well. Continue documenting whether an adult or youth made the comment and what capital is related to which comment within the square for each.

\section{The $3^{\text {rd }}$ ring question is as follows:}

- As a result of our activity (activities on the map the participants made) what changes do you see in the way community groups and institutions do things because iCook 4-H has been delivered in your area?

- Once again use a different color marker and connect this ring of comments to a capital and label comment with letter surrounded by a square, as well as if an adult or youth made the comment.

- Overall, session leader should be linking each comment in a ring to the relating comment of the beginning ring; this is so there is not a loss of connected responses throughout map.

- Once these 3 rings are completed, as a group decide what change or impact was most significant; indicate this with a starर

- Then as a group decide what activity created the most bonding for bringing the group or family together. Indicate this with a circl

- Decide which activity caused the most bridging to new people. Indicate that with a triangle.

Feedback: Also on a separate area of the board or on a piece of paper write down the group's feedback on the "whole mapping experience." This should take place after the $3^{\text {rd }}$ ring is completed.

○ A short discussion on any improvements that could be made in the future to better the current program are also welcomed.

- This ending section should be short and include final comments on any suggestions for the program to improve on.

Map Legend:

Star

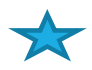

Circle
Most important or significant

Created most bonding 
Triangle

Caused most bridging with new people

" $Y$ "

Youth Participant

“ $A$ ”

Adult Participant

\section{After Discussion Wrap Up}

Thank participants for their contribution and time

Take picture of group surrounding the map, as well as REMap alone

* Give participants incentive gift cards and have them sign off on these (\$50 total: $\$ 25$

youth and $\$ 25$ adult)

○ Have participants sign off on gift cards

\section{Enter data into template}

- Record amount of time taken to record data into template format

- Record on template the session leader and note taker names for reference.

- It is recommended that the note taker together with the session leader enter and code data. Interpretations and clarity may be needed. (If data entry is not done by session leader and note taker, record name of person who entered data)

- Enter data into template as soon as possible at the end of session.

- Please save the map template with the file extension map265060lfert090115 and photoB26506Olfert090115. Send map template and photos (jpeg) to Melissa Olfert, iCook 4-H researcher at the eB4CAST data collection site, at Melissa.olfert@mail.wvu.edu.

- Attached coding template gives additional details and instructions. The coding process will help to compare themes within the data systematically with other parts.

Things to keep in mind when entering data:

- Examine one question at a time

- Find the big ideas and themes during session

- Consider the purpose of the report

- Aim for consistent language and code data accordingly

\section{Appendix Below:}




\section{Checklist:}

\section{Prior to Session}

a. Select mapping session location/venue/time/date of session

b. Determine number of participants and sessions needed

c. Session leader-complete necessary training prior to REMapping session

d. Call/email/text participants for reminder 1 week- 2 days before scheduled meeting

\section{Day of Session}

a. Arrange room layout into half-circle seating for participants

b. Debrief with team 20-30 minutes prior to review session format

c. Items needed:

\begin{tabular}{|l|l|l|}
\hline 1. Consent Forms & $\begin{array}{l}\text { 5. Whiteboard/ chalkboard/ } \\
\text { or combination of papers }\end{array}$ & $\begin{array}{l}\text { 9. Community Capitals } \\
\text { handouts for participants } \\
\text { and labels for REMap }\end{array}$ \\
\hline $\begin{array}{l}\text { 2. Demographic } \\
\text { Questionnaires }\end{array}$ & 6. Markers or chalk & $\begin{array}{l}\text { 10. Paper and pens for } \\
\text { participants }\end{array}$ \\
\hline 3. Media Release Forms & 7. Computers/labtops & 11. Gift Cards/incentives \\
\hline 4. Post-it Notes & 8. Extra paper and tape & $\begin{array}{l}\text { 12. Video camera/ audio } \\
\text { recorder/camera } \\
\text { (smartphone) }\end{array}$ \\
\hline
\end{tabular}

d. Arrange Community Capitals around map area, post-it notes for the ice breaker Q\&A, and extra sheets of paper for the brainstorming activity

\section{Arrival at Session/During Session}

a. Have participants fill out demographics questionnaire, consent form, and media release form

b. Pass out the community capitals handouts (colored and list format)

c. Introduction of session and explanation of format and what will take place

d. Ice Breaker Q\&A

e. Brainstorming Activity

f. Discussion takes place/ REMap is formed

g. Record/videotape session

i. Ripple Questions:

1. What are people doing differently as a result of

2. Who benefited from the iCook program and how?

3. As a result of our activity, what changes do you see in the way community groups and institutions do things because iCook has been delivered in your area?

ii. End of session: include any suggestions on improving program/feedback

h. Wrap-up/end session

\section{After Session}

a. Thank participants for their contribution and time

b. Take picture of group surrounding map/picture of REMap alone

c. Give participants incentive/gift cards

d. Enter/analyze data into report template

e. Send analyzed data to 


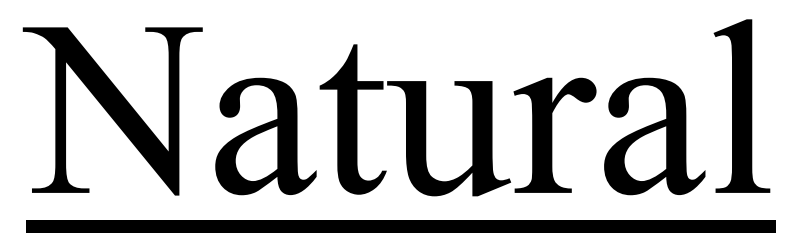

Natural resources and

natural beauty like

rivers, parks, outdoor

recreation, and

farmland

NCERA215 Social Capital Research Team including B.Baker, M. Calvert, M. Emery, R. Enfield adapted from Flora 2010 


\section{Cultural}

Activities we feel comfortable with

- Creativity including

local traditions, art and music

It also includes ways of thinking 


\section{$\underline{\text { Human }}$}

Knowledge, skills and abilities of people. Human capital also includes leadership ability and health and wellness of people 


\section{Social}

The connections

among people and

organizations that help

make things happen.

This includes bonding,

close ties; and

bridging, linking new people 


\section{Political}

Access to power and

power brokers such as

government officials,

what voices are heard

and listened to, and the

capacity of individuals

and groups to exert

power

NCERA215 Social Capital Research Team including B.Baker, M. Calvert, M. Emery, R. Enfield adapted from Flora 2010 


\section{Financial}

The monetary resources

available to invest

including business

development and

entrepreneurship as

well as philanthropy

NCERA215 Social Capital Research Team including B.Baker, M. Calvert, M. Emery, R. Enfield adapted from Flora 2010 
$\underline{\text { Built }}$

The infrastructure that

supports the community

such as

telecommunications,

roads, and buildings 


\section{Community Capitals Framework}

The Community Capitals Framework provides a way of looking at assets of a whole community. The mapping process helps groups think about how their projects might ripple out and build many assets, as a stone dropped in the pond sends ripples in every direction. A project might directly or indirectly affect all of the capitals or only a few.

\section{Natural Capital}

Cultural Capital

rurrlarl Capital

\section{Social \\ Capital}

\section{Political}

uapual

\section{Financial Capital}

- Natural resources and natural beauty like rivers, parks, outdoor recreation, and farmland.

- Activities we feel comfortable with and ways the community nurtures creativity including local traditions, art and music. It also includes ways of thinking, such as expectations the community has of youth.

- Knowledge, skills and abilities of people. Human capital also includes leadership ability and health and wellness of people.

- Connections among people \& organizations that help make things happen. This ıncluaes ponaıng, close ties tnat pulıa group mempersnıp ana sense or peıongıng, ana bridging, linking to new and varied individuals and organizations.

- Access to power and power brokers such as government officials, what voices are heard and listened to, and the capacity of individuals and groups to exert power.

- Monetary resources available to invest including business development and entrepreneurship as well as philanthropy.

- Infrastructure that supports the community such as telecommunications, roads, and buildings. 


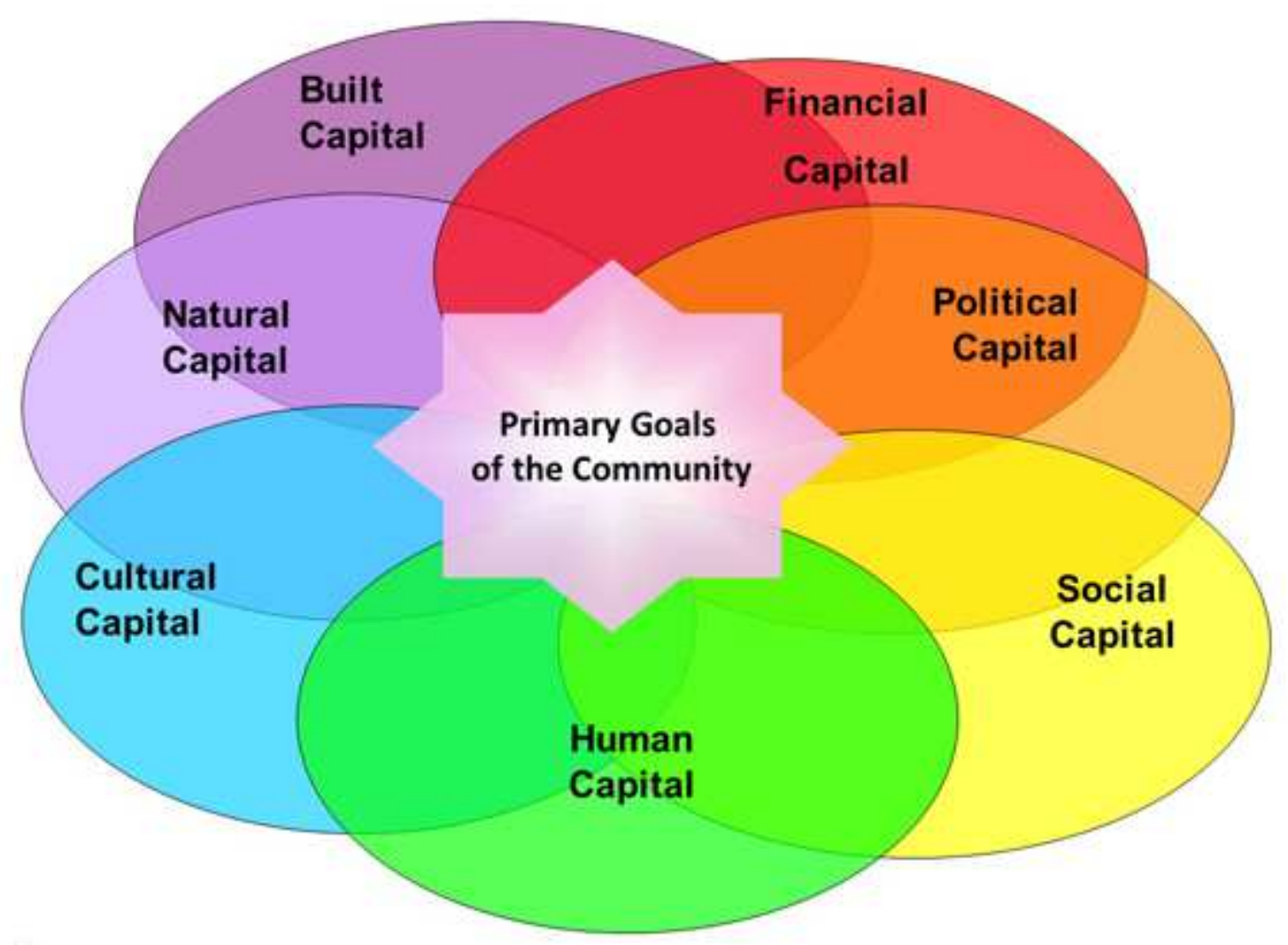




\section{APPENDIX C}

\section{Demographic Questionnaire:}

- What is your name?

- What is your iCook 4H User ID?

(The first two questions will be used solely for additional data linking if needed)

- What state do you live in? (Check correct choice)

Maine West Virginia South Dakota Nebraska Tennessee

- What is your age in years?

- What is your date of birth?

- What is your child's month of birth? (Check Correct Answer)

\begin{tabular}{|c|c|c|c|c|c|}
\hline January & February & March & April & May & June \\
\hline July & August & September & October & November & December \\
\hline
\end{tabular}

- What is your child's year of birth? (Check correct choice)

$\begin{array}{lllll}2002 & 2003 & 2004 & 2005 & 2006\end{array}$

- What is your child's day of birth?

- How many children do you have?

- What is our current marital status? (Check correct answer)

$\begin{array}{llll}\text { Married Widowed } & \text { Divorced } & \text { Single } & \begin{array}{l}\text { In a committed } \\ \text { relationship }\end{array}\end{array}$

- What is the highest education level you have completed? (Check correct choice)

\begin{tabular}{|c|c|c|c|c|}
\hline $\begin{array}{l}\text { Elementary } \\
\text { School }\end{array}$ & $\begin{array}{l}\text { Some High } \\
\text { School }\end{array}$ & High School & Some College & Associates Degree \\
\hline Bachelor's Degree & Graduate Degree & Doctoral Degree & $\begin{array}{l}\text { Choose Not to } \\
\text { Answer }\end{array}$ & \\
\hline
\end{tabular}

- What is your race? (You may choose more than 1) 


\begin{tabular}{|c|c|c|c|}
\hline White & Black & Asian & Hispanic \\
\hline
\end{tabular}

- Select one group that best represents your race? (Check correct choice)

$\begin{array}{lllll}\text { White } & \text { Black } & \text { Hispanic } & \begin{array}{l}\text { Native } \\ \text { American }\end{array}\end{array}$ Other $\begin{aligned} & \text { Choose Not } \\ & \text { to Answer }\end{aligned}$

- What is your child's race? (You may choose more than 1)

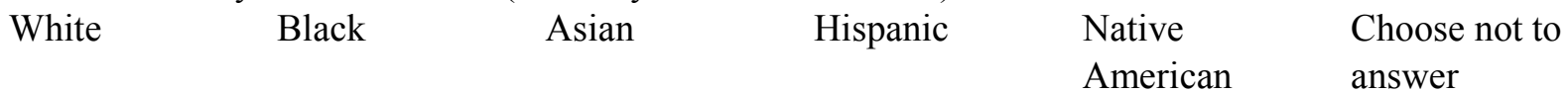

- Select one group that best represents your child's race? (Check correct choice)

White Black Hispanic $\begin{aligned} & \text { Native } \\ & \text { American }\end{aligned}$ Other $\begin{aligned} & \text { Choose Not } \\ & \text { to Answer }\end{aligned}$

- Are you the biological parent/grandparent of the child in the study? (Check best choice) Yes No

- How tall are you (feet)? (Check correct choice)

4 5

- How tall are you (inches)? (Check correct choice)

1

$\begin{array}{lll}2 & 3 & 4 \\ 8 & 9 & 10\end{array}$

5

7

$\begin{array}{lll}8 & 9 & 10\end{array}$

11

12

- How much do you weigh in pounds?

- Including yourself, how many total people live in your house?

How many are adults? How many are children under the age of 18 ?

\section{Youth Focused Questions:}

- What is your child's iCook 4H User ID?

- What is your child's name?

(The first two questions will be used solely for additional data linking if needed)

- What grade is your child in school? 
- Is your child a boy or girl? (Check correct choice)

Boy Girl

- What is your child's age in years?

- What is your child's month of birth? (Check Correct Answer)

\begin{tabular}{|c|c|c|c|c|c|}
\hline January & February & March & April & May & June \\
\hline July & August & September & October & November & December \\
\hline
\end{tabular}

- What is your child's day of birth?

- What is your child's year of birth? (Check correct choice)

$\begin{array}{llllll}2002 & 2003 & 2004 & 2005 & 2006 & 2007\end{array}$

- What is your child's race? (you may choose more than 1)

$\begin{array}{llll}\text { White Black } & \text { Hispanic } & \begin{array}{l}\text { Native } \\ \text { American }\end{array} & \begin{array}{l}\text { Choose not to } \\ \text { answer }\end{array}\end{array}$

- Select one group that best represents your child's race? (Check correct choice) White Black Hispanic Native Other American

Choose Not to Answer

- How tall is your child (feet)? (Check correct choice)

4 5

- How tall is your child (inches)? (Check correct choice)

$\begin{array}{llllll}1 & 2 & 3 & 4 & 5 & 6 \\ 7 & 8 & 9 & 10 & 11 & 12\end{array}$

- How much does your child weigh in pounds?

\section{Thank you}




\section{APPENDIX D \\ Data Report Template \\ Contribution of iCook to the Development of Social Capital (\& other capitals)}

Name of group:

Number of participants:

Note Taker:

Instructions: Enter items from the map, adding additional information where needed for context. For each item, indicate Forms of Capital: B=Built, $\mathrm{H}=$ Human, $\mathrm{F}=$ Financial, $\mathrm{S}=$ Social, $\mathrm{C}=\mathrm{Cultural}, \mathrm{N}=$ Natural, $\mathrm{P}=\mathrm{Political}$. Indicate items starred as most significant, circled as bonding activities, and marked with triangle as items that built new relationships. Insert as many additional rows as are necessary to capture the relationships in your map. If an item on the outer circle is connected to more than one inner circle item, it should be repeated to show that it is related to both. For your reference: PLEASE SEE COMPLETED SAMPLE ON NEXT PAGE (Use the table below for your project). iCook groups may chose to use these sections: "iCook: Eating, Cooking, and Playing Together".

Remember to include a photo of the group (optional: people may chose to opt out).

Context of the activity (Who was involved? (time, funds, intensity):

\begin{tabular}{|l|l|l|l|}
\hline $\begin{array}{l}\text { Activity's Short-term change. } \\
\text { What are people doing } \\
\text { differently }\end{array}$ & Who benefits and how? & $\begin{array}{l}\text { Systems and long-term } \\
\text { change. Are there changes } \\
\text { in the way community } \\
\text { groups and institutions do } \\
\text { things? }\end{array}$ & $\begin{array}{l}\text { Types of people connected. } \\
\text { How have they helped you; } \\
\text { how might they help you in } \\
\text { the future? }\end{array}$ \\
\hline PLAYING TOGETHER: & & & \\
\hline COOKING TOGETHER: & & & \\
\hline
\end{tabular}




\begin{tabular}{|l|l|l|l|}
\hline & & & \\
\hline
\end{tabular}

- Document ' $Y$ ' for youth comments and 'A' for adult comments in data entry.

- Indicate what the participants decided was a change or impact they found most significant; indicate this with a star.

- Indicate what the participants decided was the activity that created the most bonding for bringing the group or family together; indicate this with a circle.

- Indicate what the participants decided was the activity that caused the most bridging to new people; indicate that with a triangle.

- Include short feedback section at end of data; this will include the participants' feedback on the "whole mapping experience."

Map Legend: $\quad$ Include in Data Entry

Star
Circle
Triangle important or significant
Created most bonding
Caused most bridging with new people
" $A$ Youth Participant
Adult Participant

After mapping - comments/insights by participants about the mapping activity:

Ways in which the group will use this information: 


\section{APPENDIX E}

CURRICULUM VITAE of Sina King

I was born and raised in the small town of Waterford, Ohio. I graduated from Waterford High School in 2010 and began my undergraduate career at the University of Akron (UA) in Akron, Ohio as a Varsity Women's Basketball Player. During my collegiate experience, I had the honor of receiving several awards including: Senior CLASS Award Nominee, PNC Student Athlete Achiever, Bob Linton Female Student Athlete of the Year, Caroline J. Pardee Female Athlete of the Year, MAC Player of the Year, The University of Akron Presidential Scholarship, Dean's List all semesters, and three year SAAC (Student Athlete Advisory Committee) member. I was also able to participate in numerous community service activities throughout my career at UA; these experiences were extremely rewarding and my time at UA only strengthened my passion for nutrition and exercise.

At UA I received a Bachelor's of Science in Nutrition and Dietetics and a Master's of Education in Exercise Physiology. In April of 2015, I was accepted into the combined Dietetic Internship and Master's program in the Division of Animal and Nutritional Sciences at West Virginia University, as well as receiving a part-time graduate assistantship, which continued until August of 2016. This research work is in part fulfillment of earning a Master's degree projected for May 2017, followed by the opportunity to sit for the national Registered Dietetics (RD) exam. 